\section{La Révolution française}

Cahiers de l'Institut d'histoire de la Révolution française

9| 2015

Citoyenneté, république, démocratie dans la France de la Révolution

\title{
Préjugé de couleur, esclavage et citoyennetés dans les colonies françaises (1789-1848)
}

\section{Frédéric Régent}

\section{(2) OpenEdition}

\section{Journals}

Édition électronique

URL : http://journals.openedition.org/lrf/1403

DOI : $10.4000 /$ Irf. 7403

ISSN : 2105-2557

Éditeur

IHMC - Institut d'histoire moderne et contemporaine (UMR 8066)

Référence électronique

Frédéric Régent, «Préjugé de couleur, esclavage et citoyennetés dans les colonies françaises

(1789-1848) », La Révolution française [En ligne], 9 | 2015, mis en ligne le 16 novembre 2015, consulté le 01 mai 2019. URL : http://journals.openedition.org/Irf/1403 ; DOI : 10.4000/Irf.1403

Ce document a été généré automatiquement le 1 mai 2019.

(c) La Révolution française 


\title{
Préjugé de couleur, esclavage et citoyennetés dans les colonies françaises (1789-1848)
}

\author{
Frédéric Régent
}

1 En 1789, le roi de France exerce son autorité sur des établissements coloniaux qui se caractérisent par une production de denrées essentiellement assurées par des esclaves. Par ordre d'importance de la population, ces colonies esclavagistes sont: la partie française de Saint-Domingue (actuel Haïti), la Martinique, la Guadeloupe et ses dépendances (Marie-Galante, partie française de Saint-Martin, île de la Désirade, les Saintes), lîle Bourbon (île de la Réunion), lîle de France (île Maurice) et ses dépendances (Île Rodrigue et Seychelles), la Guyane, Sainte-Lucie, Tobago. Tous ces établissements coloniaux se caractérisent par l'exportation vers l'Europe de denrées (sucre, café, indigo, coton, cacao) produites par des esclaves d'ascendance africaine. Ce commerce doit se faire exclusivement sur des navires français par des négociants du royaume de France: c'est l'Exclusif. L'espace colonial français est également formé par des comptoirs de pêche (Saint-Pierre et Miquelon), de traite négrière (îles de Gorée et de Saint-Louis du Sénégal), de commerce avec l'Inde (Pondichéry, Chandernagor, Mahé, Yanaon, Karikal). Le commerce colonial français est à son apogée au début de la Révolution. La traite négrière française atteint alors son paroxysme avec plus de 54000 captifs embarqués sur des négriers français en 1790. Dans la période 1786-1790, les négociants français contribuent à environ $40 \%$ de la traite européenne, dépassant les armateurs négriers portugais et britanniques ${ }^{1}$. Les denrées coloniales et produits du commerce colonial (textiles d'Inde, épices, porcelaine...) représentent en valeur $38 \%$ des importations du royaume de France en 1787. Ces denrées sont pour une bonne part réexportées et forment $33 \%$ des exportations du royaume de France, soit autant que les produits manufacturés.

2 L'esclavage et le préjugé de couleur sont les socles des sociétés coloniales. L'esclave peut se définir comme un homme dont la liberté appartient à un autre. En effet, le propriétaire d'un esclave peut à tout moment lui redonner la liberté par le biais de l'affranchissement. 
L'esclavage enferme dans une domination totale des Africains introduits par la traite et leurs descendants. Les esclaves n'ont aucun droit, seuls leurs maitres ont quelques obligations à leur égard. Pour faire obéir l'esclave, le maitre fait utiliser le fouet, mais aussi la promesse de l'affranchissement. «Quand il accorde la liberté à un esclave, il donne de l'espoir à mille autres. C'est comme au jeu de hasard ${ }^{2}$ », selon Vertus SaintLouis, dont nous partageons l'analyse.

Les affranchis et leurs descendants forment la catégorie des libres de couleur. Les gens de couleur libre n'ont pas les privilèges des blancs. L'appartenance à une catégorie de couleur est davantage une convention socioculturelle qu'une réalité généalogique. Nos travaux ont montré que de très nombreux blancs des colonies avaient une ascendance où se mêlent Européens, Africains et Amérindiens ${ }^{3}$. "Par un assez petit nombre de générations, la couleur noire disparaît tout à fait ; j'ai vu des quarteronnes qui rivalisaient de blancheur avec les plus belles créoles; et combien, à la Guadeloupe même, la fortune et le temps en ont-ils fait passer de cette classe dans celle des Blancs ${ }^{4}$ »"

Une partie de la population métissée libre est donc rejetée de l'autre côté de la barrière de couleur par ceux qui se considèrent comme blancs. Les libres de couleur n'ont pas le droit de porter le titre de Monsieur ou de Madame, ils sont écartés de certaines fonctions (membre du conseil supérieur, officiers) et de certains métiers (avocats, médecin, pharmacien). Ils sont soumis à des arrêts somptuaires) et ne bénéficient pas de l'exemption de l'impôt de la capitation que détiennent les « blancs créoles ${ }^{5}$ ».

5 L'ensemble de ces discriminations constitue ce qui est alors appelé le préjugé de couleur. Celui-ci fonctionne comme le préjugé de noblesse ${ }^{6}$ dans la France d'Ancien Régime. A l'instar de la noblesse formée majoritairement d'anoblis, la catégorie juridique des blancs est largement formée de métissés, descendants à la fois d'Européens et de femmes amérindiennes, indiennes ou africaines. Ceux qui sont réputés blancs rejettent ceux qui n'ont pas franchi la barrière de la couleur. Ce phénomène est accentué par l'arrivée massive de pauvres immigrants blancs dans les colonies qui estiment que leur couleur est un privilège, A la fin du XVIII siècle, le préjugé de couleur se développe dans les colonies. C'est un moyen pour les autorités coloniales d'opposer deux catégories de propriétaires pour les empêcher de s'unir dans la révolte.

Tableau 1. La population des principales colonies françaises à la veille de la Révolution

\begin{tabular}{|l|l|l|l|l|l|}
\hline & Année & $\begin{array}{l}\text { Population } \\
\text { totale }\end{array}$ & $\begin{array}{l}\text { Réputés } \\
\text { blancs }\end{array}$ & $\begin{array}{l}\text { Libres } \\
\text { couleur }\end{array}$ & Esclaves \\
\hline Saint-Domingue & 1789 & Plus de 500000 & $6 \%$ & $5 \%$ & $89 \%$ \\
\hline Guadeloupe & 1789 & Plus de 100000 & $13 \%$ & $3 \%$ & $84 \%$ \\
\hline Martinique & 1789 & Plus de 100000 & $11 \%$ & $5 \%$ & $84 \%$ \\
\hline $\begin{array}{l}\text { Île } \\
\text { (Réunion) }\end{array}$ & 1788 & Autour de 50000 & $10 \%$ & $5 \%$ & $85 \%$ \\
\hline $\begin{array}{l}\text { Île de France } \\
\text { (Maurice) }\end{array}$ & 1788 & Plus de 40000 & $17 \%$ & $2 \%$ & $81 \%$ \\
\hline
\end{tabular}




\begin{tabular}{|l|l|l|l|l|l|}
\hline Guyane & 1789 & Plus de 12000 & $10 \%$ & $4 \%$ & $86 \%$ \\
\hline
\end{tabular}

6 L'un des enjeux de la Révolution française est la définition du périmètre de la citoyenneté dans le corps social. Les particularités des sociétés coloniales sont un défi aux différentes assemblées chargées de légiférer sur les droits du citoyen. Les questions coloniales font l'objet de nombreux débats parlementaires pendant toute la période de 1789 à 1799. Ainsi, les affaires coloniales s'invitent à environ une séance sur dix de l'Assemblée constituante. Il convient de préciser que ces 90 séances ne signifient pas 90 journées de discussion mais un retour du sujet colonial à 90 reprises ${ }^{7}$.

7 L'objectif de cet article est de montrer de quelle manière les différents acteurs de la Révolution vont s'emparer et traiter la question de la citoyenneté dans les colonies de 1789 à 1848. Nous retiendrons la définition du Code civil de 1804, selon lequel, la citoyenneté ce sont les droits politiques entendus comme le droit de participer à la puissance publique, ce qui inclut l'accès aux fonctions publiques aussi bien que le droit de vote.

\section{La question de la représentation des colonies aux Etats Généraux et à l'Assemblée constituante}

Les travaux de Charles Frostin ont montré que les colonies esclavagistes sont des lieux où les revendications des propriétaires réputés blancs se sont manifestées depuis le début de colonisation et surtout pendant la crise de 1768-1769, véritable «fronde de SaintDomingue » contre les dépositaires de l'autorité royale. Ils contestent alors les autorités coloniales nommées par le secrétaire d'état à la marine et aux colonies, le service dans la milice, la fiscalité et le régime de l'Exclusif ${ }^{8}$. Ce dernier interdit aux propriétaires de plantation de vendre leur production et d'acheter des produits à des navires étrangers, notamment américains, britanniques ou hollandais qui se proposent d'acheter les denrées coloniales plus chères et de vendre des produits de consommation à des prix moins élevés et souvent de meilleure qualité. Les planteurs ont utilisé les conseils supérieurs (l'équivalant des parlements du royaume de France) comme moyens d'expression de leurs revendications. Les autorités coloniales ont restreint leurs prérogatives. La suppression du conseil supérieur du Cap, en 1787, a pour effet de concentrer la justice à Port-auPrince, cristallisant le mécontentement des planteurs ${ }^{9}$. Celui-ci va désormais s'exprimer à travers les quatre chambres d'agriculture (Le Cap, Port-au-Prince, Martinique, Guadeloupe), créées en 1763. Elles sont formées de sept propriétaires créoles de grandes plantations ${ }^{10}$ nommés par le conseil supérieur. Elles font des mémoires sur les affaires économiques et adressent au ministre un rapport sur l'administration du gouverneur et de l'intendant.

9 En 1787, trois assemblées coloniales sont créées en Guadeloupe, en Martinique et à Tobago. Dans les deux premières colonies, elles remplacent les chambres d'agriculture qui sont maintenues à Saint-Domingue. Cette dernière est jugée trop agitée pour voir la mise en place de cette nouvelle institution. Aucune assemblée coloniale n'est créée dans les Mascareignes, car le ministère souhaite attendre les résultats de l'expérimentation en Guadeloupe et Martinique. Les assemblées coloniales sont composées de quatre membres de droit (gouverneur, intendant, commissaire de la marine et commandant en second), de 
32 élus en Guadeloupe et de 26 en Martinique. Sont électeurs tous les chefs de famille payant impôt, ce qui implique le vote des veuves propriétaires. Les assemblées coloniales ont pour fonction de répartir les impôts, de contrôler les travaux publics et d'adresser des mémoires au ministre.

Au moment de la convocation des Etats Généraux, les colonies ont déjà des modes de représentation. Il faut noter que de nombreux grands propriétaires de plantation ne vivent pas dans les colonies. Certains n'y ont même jamais mis les pieds. Ils confient la gestion de leurs propriétés à des procureurs-géreurs. Les propriétaires absents de SaintDomingue se forment en comité colonial, dès 1788 . Ce sont de puissants personnages, proches de la cour, liés par le sang et par l'histoire avec les premiers riches qui sont apparus à Saint-Domingue, au début du XVIII ${ }^{e}$ siècle.

11 Le 18 juillet 1788, 56 planteurs présents à Paris choisissent 9 commissaires, dont le duc de Choiseul-Praslin et le marquis de Gouy d'Arsy). Certains de ces planteurs ont un patrimoine à Saint-Domingue, d'une valeur dépassant le million de livres. Ils sont très liés aux sphères de pouvoir à Versailles ${ }^{11}$. Selon le spécialiste du droit colonial, Moreau de Saint-Méry ${ }^{12}$, "Nous voyons de plus en plus ce qu'il y a de plus illustre dans la noblesse française se confondre avec l'opulence américaine ${ }^{13}$. » La plupart des hauts fonctionnaires à la marine ont une plantation à Saint-Domingue. Ainsi, Gouy d'Arsy affirme «c'est tout Saint-Domingue qui est dans la maison du roi ${ }^{14}$.» Cette opulence du commerce colonial français confirme que la Révolution française se déclenche à un moment où le royaume de France n'a jamais été aussi riche, mais où les inégalités n'ont jamais été aussi criantes. A l'initiative de Gouy d'Arsy et de Moreau de Saint-Méry, les propriétaires de plantation résidant à Paris sont convoqués pour réclamer une représentation aux Etats Généraux et préparer une constitution pour les colonies. Le 28 septembre 1788, le comité colonial demande la création d'instances représentatives de la colonie de Saint-Domingue au sein des États généraux et une représentation coloniale locale. Ils proposent que soient élus sept députés pour chacune des trois provinces (Nord, Ouest et Sud). Ces députés seraient désignés par des grands électeurs élus par les assemblées de paroisse, à raison d'un à trois grands électeurs par paroisse, selon son importance. Pour être grand électeur, il faudrait posséder au moins 25 esclaves $^{15}$. Ce mémoire rappelle que le montant des impositions versées par Saint-Domingue s'élève à neuf millions de livres, et qu'elle contribue «à la prospérité du Royaume, à la richesse de son Commerce, en lui donnant ses productions à un prix bien inférieur à celui que lui offrirait l'étranger \& en consommant à prix très élevé le superflu des denrées de la Mère-Patrie ${ }^{16}$. »

Lorsque ce comité colonial apprend que dans la convocation des Etats Généraux, aucune représentation n'est prévue pour les colonies, il envoie des instructions aux planteurs de Saint-Domingue pour qu'ils élisent des députés. Les chambres d'agriculture de la colonie encouragent cette élection. A la mi-mars 1789, les trois provinces de Saint-Domingue ont élus des députés choisis par environ 4000 planteurs ${ }^{17}$. Le 8 juin 1789 , huit députés désignés par les grands propriétaires de Saint-Domingue résidant à Paris se présentent devant les États Généraux. Parmi eux, trois dont Gouy d'Arsy font partie du comité colonial. Ils sont admis en séance sans suffrage. Le 20 juin 1789, les meneurs du Tiers État sont en difficulté par le refus des représentants de la noblesse et du clergé de les rejoindre en une seule assemblée. Les députés des colons, menés par Gouy d'Arsy, qui revendiquent leur appartenance à la noblesse, apportent alors un soutien décisif au Tiers. Ils sont, d'une certaine manière, les premiers nobles ralliés au Tiers et vont tirer profit de cette situation. En remerciement de cette adhésion au Tiers Etat, les huit députés des 
colons sont admis à prêter le serment du Jeu de Paume ${ }^{18}$. Pourtant, les colons exigent un nombre plus important de députés à l'Assemblée Constituante en calculant leur représentation d'après la population totale des colonies comprenant aussi bien les libres de couleur que les esclaves.

Lors de la séance du 27 juin 1789 , cette demande des planteurs provoque des réactions immédiates. Brissot et Mirabeau s'élèvent avec force contre une telle représentation, qui exclut les libres de couleur propriétaires. Tandis que Gouy d'Arsy défend la représentation de Saint-Domingue, à hauteur d'une vingtaine de députés, Lanjuinais demande que les esclaves «ne puissent être considérés dans le calcul du nombre des députés de la colonie, des esclaves ne pouvant être représentés par leurs maîtres. » Cette position aurait pour conséquence de ramener la députation de Saint-Domingue à deux députés ${ }^{19}$. Alors que les colons de Saint-Domingue demandaient initialement une vingtaine de députés, ils n'en obtiennent que six. Ces derniers entrent à l'Assemblée, le 4 juillet $1789^{20}$. Le 22 septembre 1789, le nombre de députés de la Guadeloupe est fixé à deux. Le 14 octobre 1789, les planteurs de la Martinique obtiennent deux députés, dont Moreau de Saint-Méry. La Réunion et l'île Maurice obtiennent deux députés chacun, les 5 comptoirs de l'Inde, un.

14 Les colons qui sont parvenus à entrer à l'Assemblée nationale sont généralement des personnes qui gèrent leurs affaires coloniales de la capitale et qui retournent rarement dans les colonies. Pourtant, cette admission des députés est contestée par d'autres grands propriétaires absentéistes opposés à Gouy d'Arsy qui se méfient d'une représentation à l'Assemblée nationale. Le 20 août 1789, à l'initiative du marquis Mordant de Massiac, la société de correspondance des colons français est créée. Elle est plus connue sous le nom de Club de Massiac ${ }^{21}$. Les membres de ce club sont davantage des propriétaires résidant en France, dont le patrimoine repose à la fois sur des plantations coloniales et sur des seigneuries métropolitaines. Ils sont souvent impliqués dans le négoce. Ils sont par conséquent favorables au maintien de l'Exclusif. Hostiles à la représentation des colonies, ils craignent que les débats publics ne fassent la lumière sur les réalités coloniales et ne provoquent une législation remettant en cause le système esclavagiste. Afin d'échapper aux effets de la déclaration des droits de l'homme et du citoyen, alors en discussion à la fin du mois d'août 1789, le Club de Massiac avance l'idée d'une constitution spécifique des colonies $^{22}$. L'arrêté fondateur du club du 23 août 1789 précise que l'Assemblée constituante ne devrait sous aucun prétexte pouvoir influer sur les affaires de SaintDomingue. Le Club de Massiac souhaite la mise en place d'assemblées coloniales dotées d'attributions fortes. Les grands planteurs redoutent les «hésitations" ou de l'autoritarisme des administrateurs nommés par le pouvoir central qu'ils qualifient d'agents du «despotisme ministériel. » Dès le 27 août 1789, le Club de Massiac fait connaître son existence aux différentes chambres de commerce des grands ports du royaume. Le club encourage alors négociants et propriétaires de plantation à se grouper en association dans le but de réclamer au secrétaire d'état à la Marine et aux Colonies, la création d'une assemblée coloniale et de plusieurs assemblées provinciales visant à rendre Saint-Domingue plus autonome ${ }^{23}$.

Le décret que Barnave fait voter, le 8 mars 1790, assure une forme de compromis entre le Club de Massiac et la députation de Saint-Domingue en consacrant l'existence de l'Exclusif dans son principe, mais en laissant une possibilité à une éventuelle réforme. Ainsi selon l'article 6, «l'Assemblée nationale déclare qu'elle n'a entendu rien innover dans aucune des branches du commerce, soit direct, soit indirect de la France avec ses colonies.» 
Cependant, les assemblées coloniales pourront «énoncer leur vœu sur les modifications qui pourraient être apportées au régime prohibitif [...] pour être sur leur pétition \& après avoir entendu les représentations du commerce français, statué par l'Assemblée nationale ${ }^{24}$.» Le décret du 8 mars 1790 réaffirme de manière implicite le maintien de la traite négrière et institue des assemblées coloniales, là où elles n'existaient pas, à la satisfaction, à la fois des députés des colonies à la Constituante et du Club de Massiac.

L'obtention d'une députation par les représentants des riches planteurs à Paris, révèle la puissance de leur groupe de pression. En admettant les représentants des colons, les Constituants évitent l'erreur commise par le Parlement anglais qui en excluant les colons britanniques d'Amérique de toute forme de représentation avait suscité leur révolte qui avait abouti à l'indépendance des Etats-Unis ${ }^{25}$. Selon Yves Benot, le risque séparatiste a pesé sur le traitement favorable de la représentation des planteurs à la Constituante ${ }^{26}$. Quoique divisés sur cette question, le Club de Massiac et la députation de Saint-Domingue obtiennent que les assemblées coloniales puissent émettre des vœux sur le régime du commerce et des personnes. Divisés sur la question de l'Exclusif, ces deux groupes de pressions vont unir leurs forces pour s'opposer à la citoyenneté des libres de couleur à la Constituante.

\section{L'exclusion des gens de couleur de la représentation nationale}

Dans les colonies, les libres de couleur sont placés dans une situation juridique inférieure à celle des «blancs ». Malgré le préjugé de couleur, le dynamisme économique des libres de couleur est particulièrement marqué à la fin du XVIII ${ }^{e}$ siècle, à Saint-Domingue ${ }^{27}$, en Martinique et dans une moindre mesure en Guadeloupe ${ }^{28}$ et en Guyane. Il y a transfert croissant de propriétés de terres et d'esclaves des «blancs » vers les gens de couleur. Dans trois quartiers du Sud de Saint-Domingue, dans les années 1780, les libres de couleur participent à $44 \%$ des transactions foncières à la campagne ${ }^{29}$. Les libres de couleur possèdent environ $20 \%$ des esclaves de Saint-Domingue et $5 \%$ en Guadeloupe, à la fin du $\mathrm{XVIII}^{\mathrm{e}}$ siècle $^{30}$. Ceux de la Martinique sont dans une situation intermédiaire entre la Guadeloupe et Saint-Domingue ${ }^{31}$. A Saint-Denis de la Réunion, $61 \%$ des chefs de familles libres de couleur recensés possèdent des esclaves. A l'Ile Maurice, les libres de couleur possèdent $39 \%$ des propriétés ( 630 sur 1627 ) en $1810^{32}$.

Malgré ce dynamisme économique, les libres de couleur sont écartés du processus électoral des assemblées coloniales déjà existantes en Guadeloupe et Martinique ou de celles qui se mettent en place à Saint-Domingue, avant même l'arrivée du décret du 8 mars 1790. Le 15 mars 1789, les libres de couleur de la Province du Sud de SaintDomingue réclament une représentation aux Etats Généraux. Le ministre répond que c'est du ressort de l'Assemblée constituante. Les libres de couleur du Sud chargent Julien Raimond, quarteron libre ${ }^{33}$, alors en France, de suivre l'affaire. Le 26 août 1789, Julien Raimond est reçu au Club de Massiac, pour leur proposer un accord qui préserverait la traite et l'esclavage en accordant l'égalité des droits civiques aux libres de couleur ${ }^{34}$. Cette rencontre courtoise s'avère inutile. Le même jour, la Déclaration des droits de l'Homme et du Citoyen ouvre des nouvelles perspectives au quarteron libre ${ }^{35}$ de Saint-Domingue.

Le 29 août 1789, une trentaine de libres de couleur résidant à Paris se réunissent pour la première fois, dans le cabinet de l'avocat Joly (ils sont alors plusieurs centaines à résider 
dans la capitale $)^{36}$. Lors de la rédaction du Cahier, le groupe est formé de 59 libres originaires de Saint-Domingue, de 14 de la Martinique et de 4 de la Guadeloupe ${ }^{37}$. Le Cahier, contenant les Plaintes, Doléances \& Réclamations des Citoyens-libres \& Propriétaires de couleur, des Isles \& Colonies Françoises, demande à ce qu'il n'existe que deux classes d'individus, les citoyens quelle que soit leur couleur et les esclaves. Ils réclament l'affranchissement de tous les métissés pour que le soupçon d'esclavage disparaisse complètement de cette catégorie de la population. Leurs revendications semblent trouver un écho favorable dans les milieux éclairés. Le 12 octobre 1789, Brissot, membre de la Société des Amis des Noirs écrit dans le Patriote français, « l'admission des Noirs libres dans l'Assemblée nationale préparera l'abolition de l'esclavage dans nos colonies $^{38}$.»

20 Le 22 octobre 1789, les libres de couleur de Paris présentent pour la première fois leurs doléances à la représentation nationale. Ils interpellent un certain nombre d'esprits éclairés comme l'abbé Grégoire qui va bientôt les appuyer dans leur combat. Mais, ce 22 octobre 1789, le suffrage censitaire a été instauré et les libres de couleur sont écartés de la représentation nationale au motif qu'ils sont déjà représentés par les planteurs

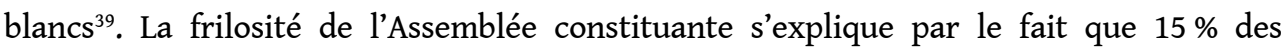
députés ont des propriétés dans les colonies et qu'un nombre encore plus grand a des intérêts dans le commerce colonial ${ }^{40}$.

21 Le 24 novembre 1789, après leurs échecs au Club de Massiac, puis devant l'Assemblée constituante, les libres de couleur se tournent vers la Société des Amis des Noirs qui poursuit une lutte en faveur de l'abolition graduelle de l'esclavage et celle immédiate de la traite. Face à la pression des planteurs et des négociants, la société philanthropique se trouve dans l'impossibilité d'abolir la traite négrière et décide de placer au premier plan de ses revendications, l'obtention de la citoyenneté pour les hommes de couleur. La Société des Amis des Noirs ne considère pas les libres de couleur comme les propriétaires d'esclaves qu'ils sont, mais comme des êtres opprimés. Le 28 novembre 1789, les Opinion sur l'admission des Nègres et Mulâtres libres aux Assemblées provinciales, pamphlet rédigé par Cocherel, un député de Saint-Domingue, défend l'idée que c'est aux assemblées des colonies de décider des modalités de la participation des gens de couleur libres aux élections. "Nous avons cru que nous devions réserver à nos frères, l'honneur de vous proposer eux-mêmes un plan d'Assemblées provinciales où ils feraient entrer d'une façon convenable nos affranchis. Par ce généreux procédé de leurs Patrons, ces affranchis en éprouveront un bienfait qui resserrera de plus en plus les liens qui les attachent à leurs protecteurs naturels ${ }^{41}$. » La générosité paternaliste remplace ici les droits de l'homme.

Le 3 décembre 1789, un nouveau débat qui porte à la fois sur la citoyenneté des gens de couleur libres et l'Exclusif a lieu, à la Constituante. Les enjeux se compliquent par les pressions contraires des Amis des Noirs (favorables à la citoyenneté des libres de couleur et hostiles à la traite et à l'Exclusif), du groupe des libres de couleur (favorables à l'esclavage et à la traite), du Club de Massiac (favorable à l'Exclusif et hostile à la citoyenneté des hommes de couleur) et la députation des colonies (hostile à l'Exclusif et à la citoyenneté des gens de couleur). Aucune décision n'est prise. La Société des Amis des Noirs décide de privilégier la défense des libres de couleur, en échange de leur soutien futur pour l'abolition de la traite. L'abbé Grégoire qui vient de rejoindre la société philanthropique décide de défendre la cause des libres de couleur dans un mémoire publié après le 3 décembre $1789^{42}$. Les positions du philanthrope sont condamnées dans un mémoire anonyme du 16 décembre 1789 : 
Il n'est pas possible que des êtres qui étaient hier dans l'esclavage, soient aujourd'hui dans les premiers rangs de la société, chargés d'emplois qui supposent l'éducation. Les mœurs et la confiance générale. On sait que les motifs d'affranchissement prennent presque tous leur source dans des sentiments que la nature inspire mais que la morale n'approuve pas toujours. Est-ce assez pour qu'on livre toutes les charges à des individus qui ne pouvant s'élever jusqu'à elles, les abaisseraient jusqu'à eux ${ }^{43}$ !

Selon cet auteur, c'est l'extraction illégitime des libres de couleur qui justifie leur exclusion des droits de citoyen. Selon Yann-Arzel Durelle-Marc, la question de l'inclusion des libres de couleur dans la citoyenneté n'est pas isolée. Les Juifs, les comédiens, les habitants de la Corse et d'Avignon posent des difficultés eux-aussi, que la Constituante peine à trancher. La Constituante débat du 21 au 24 décembre 1789 à propos du statut des Juifs et le décret du 28 janvier 1791, tout en admettant les Juifs du Sud-Ouest de la France à la citoyenneté, en exclut ceux de l'Est (Alsace-Lorraine). Il faut attendre le décret du 27 septembre 1791, pour parvenir à l'émancipation complète des Juifs de France ${ }^{44}$. Selon Yann-Arzell Durelle-Marc, la distinction entre citoyen actif et passif ne viole pas le principe d'égalité, puisque la capacité contributive n'est pas un caractère de naissance fatal et permanent ${ }^{45}$.

Le 2 mars 1790, l'Assemblée Constituante décrète la formation d'un Comité des colonies chargé spécialement de résoudre tous les problèmes coloniaux ${ }^{46}$. Aucun de ces membres ne fait partie des Amis des Noirs, alors qu'il y a deux députés de Saint-Domingue et deux négociants. Barnave, lié au monde des planteurs par ses amis, devient la figure essentielle de ce comité. Les partisans des planteurs obtiennent un grand succès avec la loi du 8 mars 1790 qui légalise les assemblées coloniales ${ }^{47}$ en leur attribuant le monopole sur la législation intérieure des colonies et sur celle du statut des personnes.

Les libres de couleur n'obtiennent pas la mention de leurs droits dans le décret du 8 mars 1790. Il est seulement précisé que sont électeurs toute personne remplissant les conditions exigées pour être citoyen actif en France. Cette rédaction floue inquiète le comité des citoyens de couleur qui réclame que le décret précise que les hommes de couleur peuvent participer à la vie politique ${ }^{48}$. Ils n'obtiennent aucun succès, pas plus que l'abbé Grégoire, lors de la rédaction des instructions du 28 mars accompagnant ce décret. Les représentants des colons et leur allié Barnave les abusent en leur assurant que les libres de couleur bénéficient des avantages de citoyens ${ }^{49}$.

26 Le Club de Massiac craint la diffusion des revendications des libres de couleur dans les colonies. Dès le 24 septembre 1789, le Club apprend par la voix d'un de ses membres que le quarteron libre Vincent Ogé, un des membres influents du groupe des libres de couleur de Paris, tenterait de rejoindre Saint-Domingue par le port de Bordeaux. Le lendemain, la société transmet l'information aux villes maritimes de France en leur indiquant les précautions à prendre afin d'empêcher les libres de couleur d'embarquer depuis l'un de leurs ports $^{50}$. Malgré cela, en juin 1790, Vincent Ogé, part pour Saint-Domingue par Londres en bénéficiant du soutien des philanthropes anglais, pour y faire valoir une interprétation favorable aux libres de couleur du décret du 8 mars 1790.

Les revendications des libres de couleur se développent aussi dans les colonies. En Martinique, à la fin du mois d'août 1789, ils rédigent un cahier de revendications dans lequel ils réclament l'égalité juridique avec les blancs. Le 28 septembre 1789, un banquet a lieu à Fort-Royal (actuel Fort-de-France) entre notables et officiers pour célébrer la prise de la cocarde tricolore. Des libres de couleur arborant la cocarde s'invitent au banquet. 
Leur entrée est refusée. Le gouverneur par intérim de la Martinique, Vioménil, indique "qu'il fallait regarder les mulâtres comme citoyens, comme confrères, et faire société avec eux, il a donné l'accolade à l'un d'eux ${ }^{51}$. " L'événement provoque une très forte hostilité à l'égard des libres de couleur, de la part de «Français, Créoles, Maltais, Ragusiens, Bergamois, Crétois, (...) et un nombre infini de demi blancs ${ }^{52}$.» Cette description de la population "blanche» de la Martinique effectuée par un libre de couleur montre le caractère cosmopolite et hétéroclite de celle-ci.

La fraternisation de Vioménil avec les hommes libres de couleur provoqua la colère des «blancs» de la ville de Saint-Pierre à son encontre. Ces derniers constituent, les 30 septembre- - $^{\text {er }}$ octobre, un comité de 18 membres, chargé de veiller aux intérêts de la ville et d'obtenir la condamnation du gouverneur. Ce comité sollicite la réunion d'une assemblée générale de la colonie pour juger les actes du gouverneur ${ }^{53}$. Vioménil autorise la réunion de l'Assemblée coloniale, le 9 octobre 1789, à Fort-Royal, afin de procéder à la convocation d'une assemblée générale pour le 16 novembre suivant. Cette assemblée générale n'a pour « unique objet » que « la nomination des représentants de la colonie auprès de l'Assemblée nationale, la rédaction des cahiers de doléances, et tous autres objets d'utilité publique.» Elle ne ferait pas, en conséquence, double emploi avec l'Assemblée coloniale, seule légalement constituée, et, se séparerait une fois l'objectif atteint. Néanmoins, il est spécifié toutefois qu'un député de l'Assemblée coloniale pouvait être aussi député de l'assemblée générale. Tout «créole et européen, portant armes, depuis l'âge de 16 ans », a le «droit de voter dans la paroisse, sur le rôle de milice » de laquelle il est porté, à condition de payer une contribution. Chaque paroisse désigne des représentants en fonction du nombre de ses habitants, à raison d'un député pour cinquante votants ${ }^{54}$.

Le 17 novembre 1789, cette assemblée générale se réunit. Elle est composée de 121 délégués. Saint-Pierre dispose de 37 ou 38 députés ${ }^{55}$. L'Assemblée soutient ouvertement le gouverneur et conteste l'idée de son jugement et de son retour en France ${ }^{56}$. Cependant, dès les 30 novembre- $1^{\text {er }}$ décembre 1789 , les représentants de la ville de Saint-Pierre, principalement des blancs "patriotes » ou "révolutionnaires », se retirent en partie de l'Assemblée générale de la colonie, dominée par les grands planteurs, car celle-ci n'a pas obtenu une représentativité correspondant à sa démographie ${ }^{57}$. Les mesures prises par l'Assemblée générale en matière d'ouverture commerciale des ports aux étrangers accentuent la rupture entre celle-ci et les patriotes de Saint-Pierre. Le conflit est renforcé lorsque l'assemblée générale de la Martinique veut contrôler les institutions municipales qui viennent de se mettre en place. Le 24 décembre 1789, sans l'accord de l'Assemblée générale, une "Commune » de 61 membres (sur le modèle de la Commune de Paris) est établie à Saint-Pierre ${ }^{58}$.

Le 22 mai 1790, les Instructions votées par l'Assemblée Nationale le 28 mars précédent, et, destinées à accompagner le décret du 8 mars 1790, arrivent en Martinique ${ }^{59}$. Ces Instructions prévoient aussi que dans les colonies où il y a déjà de telles assemblées, cellesci peuvent se dissoudre et se réorganiser après de nouvelles élections. Les patriotes et les planteurs aristocrates refusent d'accorder aux libres de couleur qui remplissent les conditions exigées pour être citoyen actif, de participer aux assemblées paroissiales pour l'élection des députés à la future Assemblée coloniale. Il en est de même, en Guadeloupe, à Sainte-Lucie et à Tobago ${ }^{60}$.

31 Les libres de couleur de la Martinique correspondent avec leurs homologues de Paris qui revendiquent l'égalité des droits. Face à ces doléances, l'hostilité des patriotes blancs des 
villes à l'égard des libres de couleur augmente. Cette animosité envers les libres de couleur de ces "petits blancs» qui se désignent comme patriotes s'explique par la concurrence économique et sociale que se livre ces deux catégories comme le souligne Pierre Dessalles. «Parmi ces hommes de couleur libres, il en existait une infinité qui vivaient du même métier que beaucoup de blancs. Ils étaient tailleurs, cordonniers, bouchers, perruquiers, marchands. Leurs boutiques étaient plus occupées, mieux servies que celle des blancs. On préférait également leur donner le commandement des différents bateaux destinés au cabotage de l'île $e^{61}$. " Le mépris que les blancs issus de métissage ont pour les libres de couleur envenime la rivalité. Ainsi Dessalles écrit : "Ceux qui les [les libres de couleur] méprisaient davantage étaient ceux qui auraient dû les ménager. Ils jouissaient, il est vrai, pour le plus grand nombre de la qualité de blancs; mais les mulâtres n'ignoraient pas qu'ils étaient de la même classe qu'eux, et que le titre dont ils s'étaient emparés était obscurci par une origine africaine. Il est étonnant combien, sur cet article, les mulâtres sont éclairés. Ils connaissent parfaitement tous ceux qui, dans la colonie, peuvent tenir à leur espèce. Ils sont mêmes en état d'en administrer toutes les preuves. Injuriés, maltraités, leur patience fut poussée à bout. Ils répandirent dans le public une liste de tous les blancs qui avaient usurpés cette qualité. On doit aisément concevoir les murmures, le mécontentement qu'occasionna cette liste parmi ceux qui se voyaient ainsi attaqués dans l'état dont ils jouissaient ${ }^{62}$. » La circulation de cette liste attise les tensions entre les « petits blancs patriotes » et les libres de couleur. La rumeur publique fait courir le bruit qu'une majorité à l'Assemblée générale se dessine pour accorder le droit de vote aux libres de couleur propriétaires en interprétant libéralement les Instructions du 28 mars 1790. Les "petits blancs " pour la plupart des Européens de passage, s'estiment être les révolutionnaires les plus ardents et réalisent que des libres de couleur aisés risquent de devenir citoyens actifs, contrairement à eux. Lors de la procession de la Fête-Dieu (3 juin 1790), les miliciens de couleur de Saint-Pierre souhaitent défiler, comme les blancs, derrière le drapeau national. Cette demande leur est refusée. Quatorze libres de couleur, trois officiers blancs des compagnies de milice de couleur qui avaient soutenu leur revendication sont massacrés et 60 à 80 emprisonnés ${ }^{63}$. Le massacre de Saint-Pierre conduit au rapprochement entre les libres de couleur et les blancs aristocrates en Martinique.

A Saint-Domingue, la situation des libres de couleur est aussi mauvaise. En novembre 1789, le sénéchal du Petit-Goâve, Ferrand de Baudières, pour avoir rédigé une pétition réclamant le droit d'envoyer un libre de couleur à l'Assemblée provinciale de l'Ouest, est décapité, sur ordre de Valentin de Cullion ${ }^{64}$. Ce dernier devient porte-parole de l'assemblée de Saint-Marc qui se réunit pour la première fois, le 25 mars 1790. A SaintDomingue, les libres de couleur sont écartés des droits civiques et victimes de nombreuses vexations dans le contexte d'un conflit entre l'administration royale et les colons rassemblés au sein de l'assemblée de Saint-Marc ${ }^{65}$. Contrairement aux assemblées provinciales de l'île, le droit de vote a été accordé à tous les «blancs » résidant à SaintDomingue depuis au moins un an. Les petits planteurs de café et d'indigo sont largement représentés. Ils écoulent leur production grâce à la contrebande et sont favorables à la fin de l'Exclusif. L'assemblée ne s'entend pas avec le gouverneur, considéré comme le représentant $\mathrm{du}$ "despotisme ministériel ${ }^{66}$. » Au lieu de publier et de faire exécuter les décrets de la Constituante, elle se déclare inviolable, établit des comités de constitution, de rapports, de législation, de commerce, de finances, d'agriculture et de correspondance (27 avril 1790). Cette tendance ouverte vers l'autonomie entraîne l'indignation des trois 
assemblées provinciales du Sud, de l'Ouest et surtout $\mathrm{du}^{\mathrm{N}} \mathrm{Nord}^{67}$, composée de riches planteurs et de négociants.

Le 28 mai 1790, l'assemblée adopte les bases d'une constitution autonomiste de SaintDomingue et se dote de la possibilité de passer des accords commerciaux avec l'étranger. Elle retire tout pouvoir au gouverneur. L'Assemblée de Saint-Marc écarte des droits civiques les libres de couleur. Nous partageons l'analyse de Manuel Covo, selon lequel, dans le projet autonomiste de Saint-Marc, les questions du préjugé de couleur et de $l^{\prime}$ Exclusif sont donc absolument indissociables ${ }^{68}$. Les travaux d'oliver Gliech montrent que l'assemblée générale est principalement composée de petits propriétaires d'habitation de café et de roturiers à la différence des riches aristocrates du Club de Massiac ou de la députation de Saint-Domingue ${ }^{69}$. Les membres de l'Assemblée de Saint-Marc sont donc en concurrence avec le dynamisme économique des plantations en café, coton et indigo appartenant aux libres de couleur. Le 20 juillet 1790, l'assemblée ouvre les ports de SaintDomingue aux navires étrangers. Une coalition composite se forme autour du gouverneur pour protester contre les «abus » de Saint-Marc. L'Assemblée du Nord est sollicitée par les négociants de la ville du Cap. Elle appelle le gouverneur Peynier à la suppression de l'assemblée générale de Saint-Marc ${ }^{70}$. Le gouverneur Peynier la dissout, le 31 juillet $1790^{71}$. Dans les autres colonies, le débat sur la question de la citoyenneté est moins conflictuel. Les libres de couleur y ont un poids numérique et économique inférieur à celui de SaintDomingue ou de la Martinique ce qui les incite à la prudence comme en Guadeloupe. Dans cette colonie, les libres de couleur se contentent de revendiquer et d'être les bras armés des factions en lutte ${ }^{72}$. En avril 1790, les deux assemblées coloniales de la Réunion et de l'Ile Maurice sont élues ${ }^{73}$. Le 5 mai 1790, les libres de couleur de l'Ile Maurice demandent à être admis à l'assemblée coloniale. Celle-ci demande aux gens de couleur de choisir deux représentants parmi les blancs y siégeant comme représentants et laisse à l'Assemblée nationale le soin de légiférer sur la question de la représentation des libres de couleur au sein de l'assemblée coloniale. Le 20 juillet 1790, les libres de couleur de l'île Maurice obtiennent le droit de vote dans les assemblées primaires, mais ne sont pas éligibles ${ }^{74}$. Les habitants de couleur de Saint-Louis du Sénégal obtiennent la satisfaction de la principale revendication de leur cahier de doléances du 15 avril 1789. Le 23 janvier 1791, l'Assemblée nationale met fin au monopole de la Compagnie de la traite de la gomme (fondée en 1785) 75. Sur le plan local, les signares (métissés) ne combattent que pour obtenir la liberté économique car ils ont déjà l'égalité politique avec les blancs. D'ailleurs, le maire de Saint-Louis, Charles Cornier est un signare. En Guyane, l'assemblée coloniale accorde la citoyenneté française aux Amérindiens qui ne se sont pas mésalliés avec des personnes d'ascendance africaine, le 5 avril 1791. La mesure ne concerne qu'un faible nombre d'individus répondant aux critères fiscaux ${ }^{76}$.

35 Le 12 octobre 1790, se tient un débat sur les «abus » de l'assemblée coloniale de SaintMarc. Barnave profite de cette discussion pour introduire un principe nouveau: l'Assemblée nationale s'interdit de délibérer sur l'état des personnes sauf si les assemblées coloniales en prennent l'initiative. Le 21 octobre 1790, Vincent Ogé débarque à Saint-Domingue. Il réclame vainement à l'assemblée coloniale du Nord l'application de la loi du 8 mars 1790 donnant implicitement l'égalité juridique aux libres de couleur. Ogé rassemble 300 libres de couleur, mais échoue dans sa révolte, car il refuse d'insurger les esclaves. Le 25 février 1791, Ogé est roué vif. Le 8 mars, 23 de ses complices sont pendus, 13 autres condamnés aux galères. 

Le 11 mai 1791, Robespierre intervient en faveur de l'égalité des droits entre citoyens blancs et de couleur. Il avance que ceci fortifiera la puissance des maîtres sur leurs esclaves $^{78}$. Le lendemain, Julien Raimond, admis à parler à l'Assemblée reprend l'argumentation ${ }^{79}$. Le 13 mai, une concession importante est faite aux colons car il est décrété comme article constitutionnel que toute loi sur l'état des personnes non-libres (les esclaves) ne pourra être faite que sur la demande formelle et spontanée des assemblées coloniales ${ }^{80}$. Le 15 mai 1791, les libres de couleur nés de père et mère libres obtiennent les droits politiques. Quant à ceux des affranchis, ils seront fixés par les assemblées coloniales. Vu l'importance du nombre des affranchis dans les colonies et les dispositions censitaires, cette mesure écarte encore de nombreux libres de la citoyenneté active. Pourtant, les députés blancs des colonies protestent contre cette loi ${ }^{81}$ qui est un des facteurs de la rupture entre Feuillants et Jacobins.

En juillet 1791, une nouvelle assemblée coloniale se réunit à Saint-Domingue, avant la réception officielle du décret du 15 mai 1791. Les libres de couleur nés de père et mère libres sont exclus de ces élections. La nouvelle assemblée est divisée entre les «petits blancs » qui se qualifient de patriotes et les aristocrates contre-révolutionnaires, proches du gouverneur Blanchelande. Les «petits blancs » dominent la ville de Port-au-Prince à partir de mars 1791. La nouvelle assemblée oblige Blanchelande, à jurer de ne pas appliquer le décret du 15 mai. Elle s'installe à Port-au-Prince et engage des démarches authentiquement sécessionnistes, à la fin d'août 1791. Son président, le marquis de Cadush propose même de livrer la colonie aux Britanniques ${ }^{82}$.

En août 1791, les libres de couleur tiennent une massive assemblée dans la province de l'Ouest, présidée par l'un d'eux, Pierre Pinchinat. Sous le commandement, notamment d'André Rigaud, les libres de couleur organisent une armée. Au début de septembre 1791, les libres de couleur mettent en déroute une troupe de "petits blancs " patriotes près de la Croix-des-Bouquets. Le 11 septembre 1791, les aristocrates de l'Ouest de SaintDomingue passent des accords avec les libres de couleur à la Croix-des-Bouquets. Une autre convention est signée entre les libres de couleur et les « petits blancs » patriotes de Port-au-Prince, le 23 octobre 1791. Les concordats prévoient la mise en place du décret du 15 mai 1791 et la disparition des distinctions de couleur dans la vie publique ${ }^{83}$.

Le comité des colonies profitant de la vague réactionnaire de l'été 1791, obtient l'abrogation de la loi du 15 mai 1791, le 24 septembre 1791, malgré l'opposition du député de l'île de France (Maurice), Pierre Antoine Monneron ${ }^{84}$, et le discours de Brissot en faveur des droits des libres de couleur au club des Jacobins, le 12 septembre ${ }^{85}$. A la nouvelle de l'abrogation de la loi du 15 mai 1791, l'assemblée coloniale de Saint-Domingue annule les concordats, le 5 novembre 1791.

Le refus d'accorder la citoyenneté aux libres de couleur s'explique par la concurrence économique et sociale qu'ils exercent à l'égard des «blancs » du petit peuple, des maîtres artisans, des marchands et des propriétaires de plantation de culture secondaire (caféières, indigoteries, cotonneries), possédant jusqu'à quelques dizaines d'esclaves. Dans les milieux aristocratiques, la défiance à l'égard des libres de couleur s'assimile davantage à un mépris nobiliaire, teinté de paternalisme, à l'égard d'individus qui tirent leurs origines de la bâtardise. Ce sont là les ressorts traditionnels du préjugé de couleur, pendant colonial du préjugé de noblesse. 
41 Peu à peu, au préjugé de couleur s'ajoute un proto-racisme à Saint-Domigue. Ainsi, en 1790 , le baron de Beauvois avance l'idée qu'il y a deux espèces d'hommes, la blanche et la rouge ; que les nègres et mulâtres n'étant pas de la même nature que le blanc, ne peuvent prétendre aux droits naturels pas plus que l'Orang-outang; qu'ainsi Saint-Domingue appartient à l'espèce blanche. Beauvois affirme que « la preuve que le nègre n'est pas de la même espèce du blanc, c'est que les mulâtres, qu'il appelle une espèce surnaturelle, ne font entr'eux que des mulâtres. " Il avance que la « liberté des nègres \& leurs possessions, ainsi que les propriétés immobilières des mulâtres, lui paraissent un abus dangereux \& ce qui est bien pis, comme nulles ${ }^{86}$. " Selon l'historien Madiou, ces idées permirent à Beauvois, membre de l'assemblée provinciale du Nord, d'être élu à la seconde assemblée coloniale $^{87}$. Les idées fixistes de Beauvois qui affirme s'inspirer de la classification de Linné sont très différentes de celles de Moreau de Saint-Méry, pour lequel les descendants d'un noir ne s'unissant qu'avec des blancs deviennent blancs au bout de sept générations, s'inscrivant dans la pensée régénératrice de Buffon. Le contexte révolutionnaire mêlé à la concurrence sociale et l'idéologie raciste fixiste naissante expliquent la violence avec laquelle la citoyenneté des libres de couleur est combattue à Saint-Domingue.

\section{L'obtention de la citoyenneté active par les gens de couleur libres}

Le 19 janvier 1791, Jean-Baptiste Caniquit et le mari de sa sœur, Pierre Chauvel, demandent au Conseil souverain (Conseil Supérieur) de Guadeloupe de « dire \& déclarer que la souche des Caniquit est réellement blanche, que les suppliants sortent de la branche qui s'est conservée dans la qualité de blancs, et qu'ils jouiront dans la colonie de tous les droits de citoyens actifs ${ }^{88}$. " Dans une autre affaire, Antoine Aurange est écarté des listes électorales, en Guadeloupe. La rumeur publique répand encore qu'il est mésallié avec une femme métissée. Il conteste cela devant le Conseil souverain. Le 10 janvier 1791, celui-ci statue et déclare « l'épouse du demandeur et leurs enfants, blancs, issus de blancs, sans aucune tache de mésalliance ${ }^{89}$. " L'un des moyens adoptés par certains métissés et d'essayer de passer pour blancs pour devenir citoyen.

Le 7 septembre 1791, la décision du 15 mai est immédiatement appliquée à l'Île Maurice, colonie d'origine du député Pierre Antoine Monneron qui a joué un rôle décisif dans son adoption $^{90}$. De son côté, Bertrand, député de la Réunion s'est associé aux députés des colons des Antilles pour exiger la suppression du décret du 15 mai, obtenue le 24 septembre 1791.

L'annonce de l'insurrection des esclaves du Nord de Saint-Domingue et la présence à l'Assemblée législative de membres influents de la Société des Amis des Noirs comme Brissot relance le débat sur la citoyenneté des gens de couleur libres. Le $1^{\text {ère }}$ décembre 1791, Brissot affirme que « la cause des hommes de couleur est donc la cause des patriotes et de l'ancien Tiers Etat, du peuple, enfin, si longtemps opprimé [...] les hommes de couleur qui réclament l'égalité des droits politiques avec les blancs, leurs frères, sont presque tous, comme eux, libres, propriétaires et contribuables ${ }^{91}$." Finalement, les libres de couleur obtiennent gain de cause par le décret du 28 mars 1792, sanctionnée par le roi et devenant la loi du 4 avril. C'est d'ailleurs Julien Raimond, membre du nouveau comité des colonies de la législative qui en propose la rédaction. 
Désormais l'égalité des droits des libres de couleur dans le cadre censitaire de la Constitution est reconnue.

A Saint-Domingue, le conflit violent reprend dans une nouvelle configuration opposant les "petits blancs» radicaux de Port-au-Prince aux libres de couleur alliés aux aristocrates. Ces derniers entretiennent souvent des liens de parenté (le plus souvent père naturel et enfant illégitime) ou de clientèle avec les libres de couleur. Le 21 novembre 1791, des affrontements ont lieu à Port-au-Prince, la ville est incendiée. 800 maisons sont détruites. «Petits blancs » et libres de couleur s'accusent mutuellement de l'incendie. Les libres de couleur, furieux contre les "petits blancs», leur livrent désormais une véritable guerre dans le Sud et l'Ouest de Saint-Domingue. En mars 1792, les «petits blancs» radicaux qui ont levé des recrues parmi les esclaves attaquent le camp des libres de couleur, alliés aux aristocrates à la Croix-des-Bouquets. Ils sont repoussés grâce à l'intervention d'une armée de 10 à 15000 esclaves armés de bâtons et de machettes ${ }^{92}$. Ces affrontements entraînent l'extension de l'insurrection servile aux provinces du Sud et de l'Ouest en raison des recrutements de soldats esclaves, suivis de démobilisations hasardeuses. Dans ce contexte, le 27 mai 1792, l'assemblée coloniale de de Saint-Domingue déclare qu'elle appliquerait la loi du 4 avril 1792, dès qu'elle en serait officiellement notifiée ${ }^{93}$. Les assemblés coloniales de Guadeloupe et de la Martinique font de même, respectivement les 31 mai 1792 et 3 juin 1792. Cette acceptation s'explique par la victoire militaire des libres de couleur, parachevée, en juillet 1792, par la prise aux " petits blancs radicaux » de Port-au-Prince par une coalition formée de libres de couleur, d'aristocrates et dirigée par le gouverneur Blanchelande. Le 5 juillet 1792, l'assemblée provinciale de l'Ouest fait savoir qu'elle a promulgué la loi dès son arrivée officielle ${ }^{94}$.

Le 17 septembre 1792, une commission civile formée de Sonthonax ${ }^{95}$ et Polverel ${ }^{96}$, munie d'importants pouvoirs et d'une force armée de 6000 hommes, débarque au Cap. Dans sa proclamation du 24 septembre la commission civile indique qu'elle est chargée d'appliquer la loi du 4 avril sur l'égalité des libres de couleur et de maintenir l'esclavage. Toutefois, il faut noter que ces deux hommes proches de Brissot sont favorables à l'abolition graduelle de l'esclavage. Le 12 octobre 1792, les commissaires civils suppriment les assemblées existantes. L'assemblée coloniale est remplacée par un comité intermédiaire de six blancs nommés par les membres de l'ancienne assemblée coloniale et de six libres de couleur désignés par les commissaires. À Saint-Domingue, la loi du 4 avril 1792 ne s'applique que là où les commissaires civils ont des forces militaires fidèles pour le faire. A Jacmel dans le Sud, en novembre 1792, les citoyens de couleur de la ville la fuient et ceux des alentours refusent de s'y rendre pour y former une municipalité, en raison des menaces des blancs ${ }^{97}$. A Port-au-Prince, le marquis de Borel, un contrerévolutionnaire prend le contrôle de la ville à la fin de 1792 et refuse d'appliquer la loi du 4 avril. Les commissaires civils ne reprennent la ville que, le 14 avril 1793, après un intense bombardement ${ }^{98}$.

En Guadeloupe, l'application de la loi du 4 avril 1792 est immédiate. L'Assemblée générale de la colonie l'approuve le $1^{\mathrm{er}}$ juin suivant. Le 4 juin, le gouverneur «appelle à de nouvelles assemblées primaires ouvertes à tous les citoyens pour le 24 juin ${ }^{99}$. » Ce jour, les assemblées primaires désignent une nouvelle Assemblée coloniale et renouvèlent les municipalités sans qu'aucun citoyen de couleur n'y soit néanmoins élu. Le faible nombre de libres de couleur répondant aux critères censitaires explique ce résultat. L'Assemblée coloniale de la Martinique, en dépit des sollicitations du gouverneur Behague, qui souhaite convoquer les assemblées primaires pour une nouvelle élection des 
municipalités et de la dite assemblée, affiche sa volonté de se maintenir dans sa composition actuelle, sans permettre aux nouveaux citoyens libres de couleur de s'exprimer enfin par un premier vote ${ }^{100}$.

48 Le 10 août 1792, le roi est renversé. Le décret du 22 août 1792 proclame pour la première fois : « les colonies font partie intégrante de l'Empire français, [...] tous les citoyens qui les habitent sont, comme ceux de la métropole, appelés à la formation de la Convention nationale.» En Guadeloupe et Martinique, les assemblées coloniales dominées par les grands planteurs entraînent les colonies dans la contre-révolution. Les patriotes sont proscrits. En Martinique, des libres de couleur commencent à se défier du gouverneur Behague et de l'assemblée coloniale. Ils se plaignent que la loi du 4 avril 1792, donnant l'égalité entre blancs et libres de couleur ne soit pas pleinement appliquée. En effet, dans les registres paroissiaux, les libres de couleur sont encore mentionnées comme le nommé au lieu d'être appelé citoyen. En août 1792, une protestation dans ce sens est faite par 68 propriétaires de couleur, dont Louis Delgrès ${ }^{101}$. Le 27 septembre 1792, une délibération des miliciens libres de couleur de Saint-Pierre révèle leur abandon de la cause des aristocrates contre-révolutionnaires. Ils refusent d'obéir à l'ordre de repousser les envoyés de la Révolution. Le premier signataire du texte est Janvier Littée ${ }^{102}$. De nombreux patriotes de Guadeloupe et de Martinique se réfugient en Dominique, une île britannique, située entre les deux colonies françaises.

Le 28 octobre 1792, plusieurs centaines de citoyens proscrits réunis sur l'île britannique de la Dominique élisent les représentants de la Guadeloupe et de la Martinique à la Convention nationale. Si les autres colonies désignent aussi des députés à la Convention (15 février 1793, pour l'Ile Maurice ; 23 septembre 1793, dans la province du Nord de Saint-Domingue et 11 octobre 1793, pour La Réunion), la particularité de ce scrutin est de s'effectuer sur un territoire étranger, avec une réunion unique et directe de citoyens proscrits, sans la tenue préalable d'assemblées primaires, suivie d'une assemblée élective ${ }^{103}$. Le procès-verbal de l'élection est signé par 285 proscrits ${ }^{104}$. Parmi les signataires, il y a des libres de couleur (environ $15 \%$ des signataires) ${ }^{105}$.

Cette assemblée électorale unique désigne notamment comme député de la Guadeloupe, le notaire Elie-Louis Dupuch et parmi les députés de la Martinique, le général Coquille Dugommier, un grand propriétaire sucrier de la Guadeloupe, et le citoyen de couleur Janvier Littée ${ }^{106}$. Certains élus sont déjà en France comme Dupuch ou Coquille Dugommier. Janvier Littée entre dans l'histoire comme le premier homme de couleur membre de la représentation nationale française! Ces hommes sont d'ardents patriotes qui ont mené la lutte contre la faction aristocrate en Guadeloupe et Martinique.

51 Ces deux colonies se rallient à la République grâce à l'intervention de Lacrosse, l'envoyé de la Convention, en janvier 1793. Par une habile propagande, il a su défaire la coalition entre aristocrates et libres de couleur. Le 9 janvier 1793, les libres de couleur de la Martinique déclarent : « Loin de vouloir méconnaître la république, nous sommes prêts à lui jurer une obéissance et une fidélité inviolable ${ }^{107}$.» Avec la mise en place du suffrage universel masculin, tous les libres de couleur deviennent citoyens de couleur. Les plus fidèles au parti aristocratique quittent la Guadeloupe et la Martinique.

La loi du 4 avril 1792 n'a que peu d'incidences sur la participation aux institutions politiques des libres de couleur dans les colonies, jusqu'à la chute de la monarchie. Toutefois, à Saint-Domingue et en Martinique, les libres de couleur ont acquis une solide expérience militaire. A Saint-Domingue, beaucoup sont devenus officiers dans l'armée ou la garde nationale. C'est avec la chute de la Monarchie et la mise en place du suffrage 
universel masculin que les libres de couleur entrent pleinement dans la citoyenneté. Ils vont majoritairement se positionner du côté de la République. De janvier 1793 à avril 1794, les libres de couleur vont participer activement à la vie politique des deux colonies en siégeant dans les municipalités, dans les assemblées administrant les colonies (Commission générale extraordinaire en Guadeloupe et Assemblée représentative de la Martinique), dans les comités de surveillance et dans les sociétés populaires, à l'instar de la Société des Amis de la République française, en Guadeloupe ${ }^{108}$ ou du « Club des Amis de la Convention et de la République française » de République-ville (actuel Fort-de-France) 109.

\section{D'esclaves à citoyens}

53 L'esclavage qui en principe n'existait pas sur le sol français sous l'Ancien Régime a été aboli par le décret du 28 septembre 1791 qui dispose dans son article $1^{\text {er }}$ que "Tout individu est libre aussitôt qu'il est entré en France » et dans son article 2 que "Tout homme, de quelle couleur qu'il soit, jouit en France de tous les droits de citoyen, s'il a les qualités prescrites par la Constitution pour les exercer». Les colonies étant placées en dehors du champ d'application de la constitution, elles ne sont pas concernées par cette disposition.

Si la question des droits des libres de couleur est réglée à Paris, celles de la traite et de l'esclavage restent en suspens. Brissot écrit le 26 janvier 1793 : «L'abolition immédiate de l'esclavage serait une calamité, mais l'abolition graduelle est utile et nécessaire : tout pays cultivé par l'esclavage doit l'être encore mieux par des mains libres ${ }^{110}$.» $\mathrm{Au}$ printemps 1793, la question de la guerre est au cœur des préoccupations des Brissotins qui veulent s'assurer le soutien des milieux négociants. Celle de l'esclavage les préoccupe encore, mais les Brissotins ne mettent pas tout leur poids politique pour avancer sensiblement vers l'abolition de l'esclavage. Qu'en est-il du côté de leurs adversaires Montagnards?

Les Montagnards lorsqu'ils renversent les Brissotins le 2 juin 1793, ne saisissent pas l'occasion qui leur est donnée d'abolir l'esclavage. En effet, le 4 juin 1793, une délégation formée de sans-culottes et d'hommes de couleur conduite par Chaumette réclame l'abolition de l'esclavage ${ }^{111}$. La Convention renvoie la demande au comité colonial (où Marat siège aux côtés de Grégoire). Cependant, celui-ci n'a plus que quatre membres, les autres étant en mission et il ne peut valablement délibéré. Dans une lettre du 24 juin 1793, les députés de l'Ile Maurice, Cossigny et Broutin affirment que la pétition est l'œuvre du gouvernement anglais qui cherche à détruire les colonies et le commerce français. Ils insistent sur le risque que cette pétition peut provoquer la guerre civile dans les colonies restées paisibles.

En France, la révolte des esclaves de Saint-Domingue est présentée dans la presse comme une seconde Vendée ${ }^{112}$. L'insurrection des esclaves vécue comme une insurrection royaliste, modifie l'approche des républicains de la question de l'esclavage. Certains d'entre eux ne veulent pas récompenser des esclaves révoltés en abolissant l'esclavage. En effet, à Saint-Domingue, les révoltes des esclaves se poursuivent et reçoivent même le soutien de l'Espagne et de la Grande-Bretagne, entrées en guerre avec la République, au début de 1793. La colonie espagnole de Santo-Domingo est frontalière de Saint-Domingue. Cette dernière est séparée par la mer de $200 \mathrm{~km}$ de la colonie britannique de la Jamaïque. 
Ainsi Toussaint Louverture, esclave noir affranchi avant la Révolution, est alors officier de l'armée du roi d'Espagne.

En juin 1793, un nouveau conflit s'ajoute aux précédents. Le nouveau gouverneur Galbaud débarque au Cap français. Natif de Saint-Domingue, il est à la fois propriétaire de plantation, fondateur du Club des Jacobins de Strasbourg, en 1790 et un des héros de la campagne contre l'Autriche en 1792. Il se trouve presque malgré lui, à la tête d'une coalition hétéroclite de mécontents formés de soldats non payés, de marins, de planteurs réfugiés dans la ville du Cap. Il s'oppose aux commissaires Sonthonax et Polvérel. Les partisans de Galbaud prennent le contrôle du Cap, le 20 juin 1793. Le lendemain, pour assurer leur défense, les commissaires civils déclarent que « la volonté de la République française et celle de ses délégués est de donner la liberté à tous les nègres guerriers qui combattront pour la République, sous les ordres des commissaires civils, tant contre les Espagnols que contre les autres ennemis soit de l'intérieur, soit de l'extérieur. [...] Tous les esclaves qui seront déclarés libres par les commissaires par les délégués de la République seront les égaux de tous les hommes libres blancs ou de toute autre couleur. Ils jouiront de tous les droits appartenant aux citoyens français ${ }^{113}$."

Il s'agit d'une attribution massive de la citoyenneté à 10000 esclaves parmi lesquels un millier est recruté et enrégimenté dans un bataillon appelé « garde des mandataires de la Convention nationale. » L'octroi de la citoyenneté suit immédiatement l'engagement militaire, à la différence des affranchissements donnés précédemment, à l'issue d'un long service armé. Forts de l'appui de ces nouveaux citoyens, Sonthonax et Polvérel reprennent le contrôle de la ville du Cap-Français, le 21 juin 1793. Les combats sont particulièrement violents. Jeremy Popkin estime le nombre de morts de 3000 à 10000 , ce qui en fait la journée la plus sanglante de la Révolution. 5000 à 10000 réfugiés et matelots fuient Saint-Domingue ${ }^{114}$.

Le 11 juillet 1793, pour garder la loyauté de leurs nouveaux soldats, les commissaires civils promettent la liberté à leurs femmes et leurs enfants, pourvu qu'ils se décident à se marier d'après les lois françaises ${ }^{115}$. Quelques temps après, Polverel regagne la province de l'Ouest et Sonthonax reste seul au Cap. Le 27 août 1793, Polverel proclame, pour la province de l'Ouest, que tous les « Africains et descendants d'Africains, de tout sexe et de tout âge [...] seront déclarés libres et jouiront dès à présent de tous les droits des citoyens français sous la seule condition de s'engager à continuer de travailler à l'exploitation " des plantations des adversaires de la République et des émigrés. Cette décision quoique limitée aux plantations abandonnées par leurs propriétaires, concernent plus de la moitié des esclaves, vu le nombre d'émigrés ${ }^{116}$. Cette mesure qui ne concerne que les esclaves des émigrés est prise pour que les propriétaires d'esclaves ralliés à la République, le restent et notamment les citoyens de couleur, nombreux dans l'Ouest, depuis leurs victoires à Portau-Prince, en juillet 1792 et avril 1793. Le 29 août 1793, sans concertation, avec son homologue, Sonthonax proclame dans la province du Nord de Saint-Domingue « que tous les nègres et sang-mêlés, actuellement dans l'esclavage, sont déclarés libres pour jouir de tous les droits attachés à la qualité de citoyen français ${ }^{117}$. » Cette mesure aurait été prise sous la menace des esclaves-soldats insurgés au service des Espagnols. Polverel invite les propriétaires d'esclaves républicains à affranchir leurs esclaves, le 21 septembre 1793, pour la Province de l'Ouest et le 7 octobre 1793, pour celle du Sud. Cette invitation est suivie de décisions individuelles ou municipales d'affranchissements ${ }^{118}$. Le 31 octobre 1793, Polverel proclame l'octroi de la citoyenneté à tous les esclaves de l'Ouest et du Sud. Cette proclamation institue une gestion démocratique dans les plantations. Les 
conducteurs de travaux, nouvelle appellation des commandeurs ${ }^{119}$, ne sont plus nommés par les propriétaires ou gérants, mais élus par les cultivateurs. Le gérant est choisi par le propriétaire sur une liste de deux candidats choisis par les cultivateurs. La plantation est gérée par un conseil d'administration compose du gérant et des conducteurs de travaux. Il est prévu des instituteurs pour enseigner la lecture, l'écriture, le calcul, les droits et devoirs du citoyen aux enfants ${ }^{120}$. Ce sont donc deux textes différents qui s'appliquent à Saint-Domingue entre la Province du Nord et celles de l'Ouest et du Sud.

L'abolition de l'esclavage entraîne la défection de nombreux blancs. Ces derniers accueillent chaleureusement les Britanniques qui débarquent à Jérémie (province du Sud) et au Môle Saint-Nicolas (province du Nord) à la fin de septembre $1793^{121}$. Les ports de l'Ouest, Saint-Marc et Arcahaye, se livrent aux Britanniques avec la bénédiction des citoyens du 4 avril qui refusent l'abolition de l'esclavage. Toussaint Louverture reste fidèle au roi d'Espagne et reproche l'exécution de Louis XVI à la République. S'adressant aux commissaires civils, il déclare, en août 1793: «Vous nous faites entrevoir que la Liberté est un bien, que nous en jouirons, en nous soumettant à l'ordre [...] Mais tant que Dieu nous donnera la force et les moyens, nous acquerrons une autre Liberté, différente que celle que vous prétendez, tyrans, nous imposer ${ }^{122}$. » Une bonne partie de ceux qui se sont joints aux forces républicaines au moment de la crise de 20 juin 1793 les abandonnent peu après. Le 27 octobre 1793, Sonthonax se plaint du fait qu'il n'a pas pu gagner l'adhésion des anciens esclaves à la République : «L'idée d'un roi est simple, elle est à la portée du plus stupide des Africains ; les plus instruits d'entr'eux ne conçoivent pas celle d'une république [...] Les principes de la convention leur sont tellement étrangers que plusieurs fois ils ont proposé au Cap de me faire roi au nom de la République ${ }^{123}$.»

61 Pourtant, Dufay (blanc), Mills (mulâtre), Belley (noir), élus députés de la province du Nord, le 22 septembre 1793, obtiennent de la Convention la ratification des mesures abolitionnistes des commissaires civils, le 4 février 1794. Selon Dufay qui prononce un long discours, les esclaves méritent d'être citoyens car ils ont combattu par les armes pour la République ${ }^{124}$. Le décret de la Convention du 4 février 1794 dispose que "l'esclavage des Nègres dans toutes les colonies est aboli : en conséquence elle décrète que tous les hommes, sans distinction de couleur, domiciliés dans les colonies, sont citoyens Français, \& jouiront de tous les droits assurés par la constitution.» Le 12 avril 1794, le Comité de Salut Public ordonne l'expédition du décret du 4 février à l'ensemble des colonies.

62 Aux Antilles, la situation est désespérée pour la République. En avril 1794, les Britanniques se sont emparés de la Martinique, de la Guadeloupe et de la plupart des ports de l'Ouest de Saint-Domingue. Toutefois, l'officialisation de l'abolition de l'esclavage par la Convention a pu favoriser la volte-face de Toussaint Louverture qui, avec ses 4000 soldats, rejoint le camp républicain, le 18 mai 1794. Les bandes d'esclaves armés suivent les choix politiques de leur chef. Selon David Geggus qui hésite entre deux explications, Louverture a pu choisir de se rallier à une France désormais symbole de la liberté générale ou a voulu quitter une armée espagnole dans laquelle sa carrière était en train de s'enliser ${ }^{125}$. Le ralliement de Toussaint Louverture est un élément décisif du maintien de la France à Saint-Domingue. Îles du Vent (Guadeloupe, Martinique, Sainte-Lucie), alors occupée par les Britanniques. Le 7 juin 1794, Victor Hugues proclame l'abolition de l'esclavage en Guadeloupe. De juin à 
décembre 1794, il parvient à faire la reconquête de la Guadeloupe, en incorporant massivement les anciens esclaves dans l'armée. Mieux, l'armée de Guadeloupe s'empare momentanément de Sainte-Lucie, de la Grenade, de Saint-Martin, de Saint-Eustache et de Saint-Vincent en 1795. Le 14 juin 1794, l'abolition de l'esclavage est aussi proclamée en Guyane, restée française. Dans cette colonie, le nombre d'esclaves est réduit et les capacités de résistance des propriétaires à cette mesure sont limitées. Le 18 juin 1796. Baco et Burnel, deux agents chargés d'abolir l'esclavage aux Mascareignes, y débarquent. Trois jours plus tard, ils sont embarqués de force par les planteurs qui refusent l'application de l'abolition de l'esclavage. Le décret d'abolition de l'esclavage du 4 février 1794 n'est appliqué ni aux Mascareignes, où les colons sont assez puissants pour repousser les envoyés de la Convention, ni en Martinique car l'île est restée sous occupation britannique.

Le contexte de guerre avec le reste de l'Europe, qui a d'abord été un obstacle à l'abolition graduelle de l'esclavage permet finalement l'abolition immédiate de l'esclavage. Toutefois, la liberté générale n'a été proclamée que là où les esclaves ont été armés massivement ${ }^{126}$. La citoyenneté au sens de la constitution de 1793 a été proclamée pour les anciens esclaves, mais dans la limite des règlements de culture ou des proclamations coercitives, engageant les anciens esclaves à poursuivre leur ancien travail.

\section{Les nouveaux principes de la citoyenneté dans les colonies pendant le Directoire}

Après la chute de Robespierre, les conventionnels élaborent la Constitution du 5 fructidor an III (22 août 1795). Dans ses articles 6 et $7^{127}$, les colonies sont assimilées au socle national. La loi du 25 octobre 1797 (4 brumaire an VI) transforme les colonies en départements français ${ }^{128}$. Il y a donc dans la législation du Directoire, volonté de permettre les mêmes modalités d'accès à la citoyenneté sur le territoire européen de la République et dans l'outre-mer. Voici les dispositions principales de cette constitution de 1795 qui appelle citoyen seulement ceux qui réunissent les conditions pour détenir le droit de vote.

Art. 8 : Tout homme né et résidant en France, qui, âgé de vingt et un ans accomplis, s'est fait inscrire sur le registre civique de son canton, qui a demeuré depuis pendant une année sur le territoire de la République, et qui paie une contribution directe, foncière ou personnelle, est citoyen français.

Art. 9: Sont citoyens, sans aucune condition de contribution, les Français qui auront fait une ou plusieurs campagnes pour l'établissement de la République. [...] Art. 10: L'étranger devient citoyen français, lorsque après avoir atteint l'âge de vingt et un ans accomplis, et avoir déclaré l'intention de se fixer en France, il y a résidé pendant sept années consécutives, pourvu qu'il y paie une contribution directe, et qu'en outre il y possède une propriété foncière, ou un établissement d'agriculture ou de commerce, ou qu'il y ait épousé une femme française.

Une loi spécifique, celle du 12 nivôse an VI ( $1^{\text {er }}$ janvier 1798) est adoptée pour préciser les modalités d'application de l'accès à la citoyenneté dans les départements d'outre-mer. Elle est une réaction républicaine à la tendance à la restauration de l'ordre colonial traditionnel qui s'est manifestée au printemps et à l'été $1797^{129}$. Pour voter aux assemblées primaires, il faut payer une contribution égale à trois journées de travail agricole (article 19) ou avoir participé à une campagne militaire de la Révolution (article 20). Elle précise que "les individus noirs ou de couleur, enlevés à leur patrie et 
transportés dans les colonies, [...] jouissent des mêmes droits qu'un individu né sur le territoire français, s'ils sont attachés à la culture, s'ils servent dans les armées, s'ils exercent une profession ou métier» (article 15). A partir de l'application de la loi du $1^{\mathrm{er}}$ janvier 1798, "tout individu noir, né en Afrique ou dans les colonies étrangères, transféré dans les îles Françaises, sera libre dès qu'il aura mis le pied sur le territoire de la république ", mais pour acquérir le droit de citoyen français, il devra se conformer aux dispositions de la constitution concernant les étrangers ${ }^{130}$

Selon Yerri Urban, « la loi du $1^{\mathrm{er}}$ janvier 1798 créé une situation complexe par rapport au décret du 16 pluviôse. Il y a ainsi un double aménagement: d'une part, les nouveaux libres nés en Afrique ne sont français par leur domicile que s'ils ont une activité, d'autre part, à l'avenir, les esclaves africains ou de colonies affranchis par le sol français seront considérés comme des étrangers. Une constante demeure dans le discours républicain, la citoyenneté des nouveaux libres est fréquemment conçue comme une compensation, une réparation des horreurs de la traite et de l'esclavage.

L'autre originalité de la loi du $1^{\mathrm{er}}$ janvier 1798 , c'est la privation de la citoyenneté pour vagabondage pour toute personne jusqu'à ce qu'elle ait repris la culture, un métier ou une profession (article 16). Sera réputé vagabond tout individu qui ne pourra justifier d'un domicile et d'un état connus (article 17). Selon Yerri Urban, « l'extrême originalité de la peine prévue par l'article 16 est la privation temporaire de la qualité de citoyen qui cesse dès qu'une activité est reprise. Le but de la disposition est de toute évidence de maintenir les nouveaux libres africains dans les plantations. Est ainsi créé un statut hybride de nouveau libre africain presque Français : beaucoup parmi eux ne pourront être citoyens que s'ils renoncent à une partie de leur liberté en demeurant rattachés à une plantation ${ }^{131}$ . »

\section{La difficile application des principes de la citoyenneté dans les colonies}

Dans les colonies, où l'abolition de l'esclavage a été proclamée se pose la question de l'application de la constitution de 1795 et de ses lois d'application. Eric de Mari a évoqué la complexité de la situation à Saint-Domingue à travers l'analyse des registres notariés, indiquant qu'un même quartier pouvait connaitre à un moment la liberté générale puis quelques mois après, l'esclavage, en fonction de la présence ou non de forces républicaines ${ }^{132}$. Dans le Nord de Saint-Domingue, la proclamation de l"abolition du 29 août 1793 s'accompagne d'un règlement de culture. Il assigne à résidence sur leurs plantations respectives les nouveaux citoyens, et les soumet à un travail journalier moyennant un salaire déterminé qui équivaut au tiers du revenu des exploitations. Les domestiques et les ouvriers restent au service de leurs anciens maîtres, moyennant salaire, négocié de gré à gré. Les personnes attachées à la culture et les domestiques ne peuvent quitter leur commune, sans une permission de la municipalité. Dans l'Ouest et le Sud de Saint-Domingue, le règlement de Polverel du 7 février 1794 prévoit un vote de l'ensemble des cultivateurs de la plantation pour déterminer le nombre de jours qu'ils travailleront dans celle-ci. La part du revenu de chaque cultivateur est diminuée en fonction de la réduction de la durée du travail ${ }^{133}$. Finalement, la citoyenneté, proclamée dans l'Ouest et le Sud de Saint-Domingue, pour ceux qui restent sur la plantation de leur 
ancien maitre, est davantage une citoyenneté de l'habitation qu'une citoyenneté de la cité. En effet, aucune élection de députés n'y aura lieu pendant la Convention.

Comme dans le Nord de Saint-Domingue, en Guadeloupe, le temps de travail des cultivateurs et des domestiques reste la propriété de leurs anciens maîtres, ou à défaut de ceux-ci de la République. Le cultivateur n'a pas de liberté de mouvement sans autorisation de son maître. Il a cependant une personnalité civile qui lui permet d'accéder à la propriété, au mariage, à la justice. En pratique, peu de cultivateurs deviennent propriétaires et lorsque c'est le cas, il s'agit de biens modestes (cases sans la propriété du terrain). Sur les plantations, le nouveau libre est défini comme cultivateur destiné uniquement à la production de denrées sur lesquelles il a droit à une part dans le quart des revenus de la plantation. En ville, les domestiques et ouvriers n'ont que droit à un salaire. Seuls les libres avant le décret, les anciens esclaves qui ont réussi à ne plus être attachés au service d'une personne et payant une contribution, ainsi que ceux qui ont participé à une campagne militaire sont citoyens au sens de la Constitution de 1795.

71 En Guadeloupe, se targuant du calme qui règne dans la colonie, contrairement à l'agitation de Saint-Domingue, Victor Hugues refuse l'application de la Constitution de 1795 sous prétexte qu'elle est impraticable dans les colonies. Son argument principal est que sans la contrainte, le cultivateur refusera de travailler car en Guadeloupe, « il ne faut que dix jours dans une année pour se procurer tous ses besoins et vivre agréablement sans nuire à la société, suivant l'esprit républicain de la constitution. » Selon Victor Hugues, avec peu d'efforts, tous les cultivateurs pourraient être susceptibles de payer une contribution et donc de voter. Hugues souligne la contradiction qui existe entre l'application de la Constitution et les règlements de culture sévères qu'il a mis en place sous l'injonction du Directoire. Dans une lettre du 25 octobre 1797, Hugues rappelle que la Constitution est impraticable dans les colonies. Selon lui, « il est aussi dangereux de les faire jouir d'une grande liberté que d'un rigoureux esclavage. Il faudrait les supposer bien éclairés pour pouvoir jouir des droits de la constitution aux citoyens Français, et malheureusement ils ont à peine franchi les bornes de l'instinct. Ils ont même la férocité naturelle de tout ce qui respire en Afrique ${ }^{134}$.»

Victor Hugues refuse également d'appliquer la loi du $1^{\mathrm{er}}$ janvier 1798. Il conteste le fait que les Africains, dont les trois quarts ne parlent pas français et dont aucun ne sait écrire, puissent être citoyens français. Il s'oppose au droit de vote de ceux qui ont fait une ou plusieurs campagnes militaires pendant la Révolution: «Il n'y a jamais eu, citoyen ministre, de conseil d'administration dans l'armée des Antilles, il eût été inutile de faire délibérer des hommes qui ne savent ni parler, ni écrire. Les trois quarts des officiers du bataillon sont dans ce cas $^{135}$. » En refusant d'appliquer la Constitution de 1795 et les lois sur les colonies, Victor Hugues souhaite conserver le caractère personnel de son régime. Ni la Constitution, ni l'esclavage, tel est le mot d'ordre de l'agent du Directoire.

73 A Saint-Domingue, des élections au Corps législatif ont lieu en septembre 1796 et avril 1797. Ces élections sont troublées au vu des procès-verbaux qui nous sont parvenus. En effet, le choix des députés aurait été dicté par le despotisme militaire de Toussaint Louverture qui contrôle alors militairement le Nord. Pierre Pinchinat, un proche d'André Rigaud, le général mulâtre qui domine, alors le Sud porte les accusations suivantes contre les opérations électorales : "L'argent employé à payer les suffrages dans cette assemblée monte à cent mille livres. Plusieurs chefs militaires avaient ordre d'exiger des électeurs de leurs quartiers respectifs qu'ils ne nommassent que ceux dirigés par Sonthonax. On distribuait publiquement des listes de candidats ; l'appareil de la force armée fut déployé 
comme pour cerner les électeurs, et déterminer leurs suffrages par l'influence des baïonnettes. L'intrigue et la violence furent également employées dans l'assemblée de l'an V (avril 1797); Gignoux, armé d'un gros bâton, alla jusqu'aux portes du lieu des séances, menaçant du courroux de Sonthonax ceux qui ne voteraient pas à son gré136. "

Les élections de Saint-Domingue d'abord annulées pour ces irrégularités sont validées à la suite du coup d'État du 18 fructidor an V (septembre 1797). A l'inverse, les opérations électorales du Sud, qui avaient désignés notamment Pinchinat sont annulées, en janvier 1798. Comme pour les députations antérieures, c'est le Nord de Saint-Domingue qui est représenté de façon exclusive ${ }^{137}$. En 1798, à Saint-Domingue, les généraux ont pris le pouvoir. Le général Toussaint Louveture qui domine le Nord, mais est aussi général en chef de l'armée de Saint-Domingue, depuis 1796, destitue, en octobre 1798, Hédouville, l'agent civil du Directoire. Ce dernier délivre Rigaud, général mulâtre dominant le Sud, de sa subordination à Toussaint Louverture.

Le 28 février 1799, l'agent du Directoire Desfourneaux promulgue la Constitution de 1795 en Guadeloupe. Compte-tenu de ses articles 155 et 156, Desfourneaux a le pouvoir de désigner les députés de la Guadeloupe au Corps Législatif, mais il préfère organiser une élection, la première qui se tient en Guadeloupe depuis l'abolition de l'esclavage. Le 21 mars 1799, des assemblées primaires se tiennent dans tout le département. D’après la Constitution, pour voter dans les assemblées primaires, il faut payer une contribution directe, foncière ou personnelle qui équivaut à trois journées de travail agricole. En Guadeloupe, aucun impôt de cette forme n'a été prélevé depuis 1794. Desfourneaux

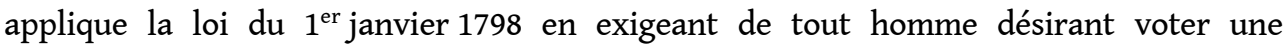
déclaration d'engagement à payer une contribution personnelle et le faire dix jours avant le scrutin. Cette mesure entraîne la défection de nombreux individus susceptibles de voter. À Pointe-à-Pitre, les compagnies formées de noirs en faction devant les assemblées primaires s'insurgent sous le prétexte que Desfourneaux veut exercer une influence sur leur vote. Il avait été accusé des mêmes faits lorsqu'il était général de division à SaintDomingue, en avril $1797^{138}$. Finalement, l'élection des quatre députés de la Guadeloupe au Corps Législatif est invalidée. Le 6 octobre 1799, Desfourneaux est destitué de ses fonctions par un putsch militaire. Toutefois, après le coup d'état de Bonaparte de novembre 1799, la constitution du 22 frimaire an VIII (13 décembre 1799) dispose dans son article 91 que «le régime des colonies françaises est déterminé par des lois spéciales. » De ce fait, en mars 1800, les assemblées primaires électorales sont ajournées en Guadeloupe ${ }^{139}$.

\section{Remises en causes et suppression de la citoyenneté pour les hommes de couleur}

Malgré une réelle volonté d'application de la loi du $1^{\text {er }}$ janvier 1798 par le Directoire, le texte sera rapidement rendu sans objet par la constitution de 1799, qui met fin à l'assimilation juridique de principe des colonies. Dans son tout premier article, de la constitution de 1799 qui prévoit que «La république est une et indivisible. Son territoire européen est divisé en départements et arrondissements communaux.» Le terme " européen " annonce d'emblée le caractère spécifique et dérogatoire de l'article 91 et, par la même occasion, le paradoxe de la présence du terme «indivisible». En effet, en 1799, la France est présentée comme un territoire européen, aucune mention n'est faite des possessions outre-mer. A travers les 14 premiers articles regroupés dans le Titre I, il 
n'est question que des citoyens vivant dans les départements et arrondissements communaux ${ }^{140}$. Il n'est donc plus question en 1799 d'appliquer dans les territoires d'outre-mer les mêmes principes de la citoyenneté que ceux des départements européens. Les colonies ne sont désormais plus représentées au corps législatif. Bonaparte se justifie en déclarant que cela « dérive de la nature des choses et de la différence des climats. Les habitants des colonies françaises situées en Amérique, en Asie, en Afrique, ne peuvent être gouvernés par la même loi. La différence des habitudes, des mœurs, des intérêts, la diversité du sol, des cultures, des productions, exigent des modifications diverses ${ }^{141}$.» C'est donc au nom des différences que s'opère la rupture avec l'assimilation juridique, appelée aussi isonomie républicaine par Bernard Gainot ${ }^{142}$ ou identité législative par les juristes spécialisés dans le droit d'outre-mer ${ }^{143}$. Bonaparte remet aussi en cause le principe de l'application uniforme de l'abolition de l'esclavage. Lors de la séance du Conseil d'État du 16 août 1800, le Premier consul déclare : « La question n'est pas de savoir s'il est bon d'abolir l'esclavage [...]. Je suis convaincu que [Saint-Domingue] serait aux Anglais, si les nègres ne nous étaient pas attachés par l'intérêt de leur liberté. Ils feront moins de sucre, peut-être, mais ils le feront pour nous, et ils nous serviront, au besoin, de soldats. Si nous avons une sucrerie de moins, nous aurons une de plus citadelle occupée par des soldats amis ${ }^{144}$.» Si au nom du pragmatisme, Brissotins et Montagnards, en dépit de leurs principes avaient tardé à abolir l'esclavage, Bonaparte agit inversement. C'est par opportunisme qu'il maintient, en dépit de son absence de convictions philanthropiques, la liberté générale là où elle a été proclamée, notamment à SaintDomingue et en Guadeloupe.

Toussaint Louverture, déjà maître du Nord de Saint-Domingue en 1798, a fait la conquête du Sud, en 1800, en sortant victorieux de sa guerre civile avec le général mulâtre André Rigaud, puis a envahi la partie espagnole, cédée à la France, lors du traité de Bâle en 1795. Toussaint Louverture adresse à Napoléon Bonaparte un texte s'intitulant «bases constitutionnelles du régime de la colonie française de Saint-Domingue ", s'inspirant de la dénomination des "bases constitutionnelles de Saint-Domingue ", adoptée par l'assemblée de Saint-Marc, le 28 mai 1790.

Les bases constitutionnelles du régime de la colonie française de Saint-Domingue ne définissent pas le citoyen de ce territoire qui n'est pas non plus déterminé pour l'outremer, dans la constitution de 1799. Le terme de citoyen apparaît seulement à l'article 21 dans les bases constitutionnelles. Auparavant les termes utilisés sont «habitants » ou " français ». Le citoyen Toussaint Louverture est nommé gouverneur à vie. Il nomme à tous les emplois civils et militaires, y compris son successeur. A partir de ce dernier, le mandat de gouverneur est de 5 ans. Celui-ci serait alors élu par la réunion de l'Assemblée centrale, des généraux de l'armée en activité et des commandants en chef des départements. L'assemblée centrale initiale est nommée par Toussaint Louverture. $\mathrm{Ce}$ dernier a seul l'initiative de la loi que l'Assemblée centrale vote. C'est une constitution dictatoriale.

Dans les bases constitutionnelles, le citoyen Toussaint Louverture est seul à l'origine de la puissance publique et seul à nommer quelques détenteurs du droit de vote. Les possibilités démocratiques données aux citoyens-cultivateurs par les arrêtés de Polverel sont supprimées. Toussaint Louverture met en place le caporalisme agraire par ces règlements de culture : il rappelle les émigrés et confie à des officiers de son armée, les plantations vacantes. Le règlement de culture du 12 octobre 1800 dispose que «tous les gérants, conducteurs et cultivateurs sont tenus de remplir avec exactitude, soumission et 
obéissance leurs devoirs comme le font les militaires. » Celui du 7 février 1801 interdit les ventes de terres de moins de 56 hectares ${ }^{145}$. La pratique du pouvoir et les bases constitutionnelles de Toussaint Louverture font disparaître la citoyenneté politique pour la quasi-totalité des habitants de Saint-Domingue.

Le 19 avril 1801, un arrêté consulaire fixe la nouvelle organisation de la Guadeloupe. Elle sera désormais dirigée par un capitaine général, un préfet colonial et un commissaire de justice. Le premier a une responsabilité militaire, le second est chargé de l'administration et le troisième est responsable du fonctionnement de l'appareil judiciaire ${ }^{146}$. Dans un premier temps, le 29 mai 1801, seul Lacrosse désigné capitaine général débarque en Guadeloupe et dispose des pouvoirs des trois fonctions. Lacrosse a le projet de supprimer toutes les municipalités et l'administration départementale, et de les remplacer par un lieutenant général de police ${ }^{147}$. En août 1801, Lacrosse destitue la municipalité de BasseTerre qu'il accuse d'avoir soutenu une mutinerie de militaires de couleur.et la remplace par un commissaire de gouvernement. La politique vexatoire de Lacrosse entraine un putsch des officiers de couleur qui le renvoie de la Guadeloupe, en octobre 1801. Un officier de couleur, le chef de brigade Magloire Pélage, prend la place de Lacrosse à la tête de l'armée. Le 21 octobre 1801, Pélage prend une initiative politique en convoquant une assemblée des notables de Pointe-à-Pitre. Elle procède à un vote avec scrutin signé pour désigner trois commissaires civils chargés avec Pélage de correspondre avec Lacrosse. Le procès-verbal de l'assemblée est signé par 240 citoyens qui sont pour la plupart blancs ${ }^{148}$.

81 Le 10 novembre, Pélage choisit cinq administrateurs provisoires pour gouverner la Guadeloupe, sous le nom de Conseil provisoire. Le 12 novembre 1801, le choix du Conseil provisoire est approuvé par l'assemblée des citoyens de Pointe-à-Pitre. Elle est composée majoritairement de blancs, mais compte quelques citoyens de couleur ${ }^{149}$. Toutes les communes ratifient cette décision par la consultation des citoyens entre le 12 et le 26 novembre ${ }^{150}$. Le ralliement au renvoi de Lacrosse est loin d'être unanime certains citoyens se plaignent d'avoir été obligés de signer les procès-verbaux des assemblées ${ }^{151}$. Les militaires, pourtant citoyens, ne votent pas, mais ils ont donné leur approbation en participant au putsch. Le caractère autoritaire du nouveau régime est confirmé par le fait que le Conseil provisoire n'attende pas l'approbation de tous les cantons pour commencer à fonctionner. Il tient sa première séance, le 15 novembre 1801. Son premier acte est de jurer fidélité à la France et au gouvernement consulaire. Le conseil envoie une lettre au Premier Consul dans laquelle il présente les membres du conseil comme les meilleurs garants d'une politique de conservation, d'ordre et de modération ${ }^{152}$. Le 16 novembre 1801, l'administration départementale centrale est supprimée. Ses fonctions sont attribuées au Conseil provisoire ${ }^{153}$.

Bonaparte après de nombreuses hésitations ${ }^{154}$ décide de soumettre Toussaint Louverture et son régime, en envoyant un corps expéditionnaire dirigée par le général Leclerc, à la fin de 1801. Il fait de même pour la Guadeloupe, avec l'expédition Richepance, en avril 1802. Selon Philippe Girard, dont nous partageons l'avis, le but de ces opérations est d'abord pour Bonaparte de se débarrasser de son rival colonial, de punir des officiers de couleur qui ont désobéi aux envoyés de la métropole et de rétablir la production. Nous ne croyons pas à des instructions secrètes ayant fixé un plan préétabli de rétablissement de l'esclavage comme certains historiens l'avancent ${ }^{155}$. En effet, la loi du 30 floréal an X (20 mai 1802) maintient dans les colonies restituées par la Grande-Bretagne lors du traité d'Amiens (Martinique, Sainte-Lucie, Tobago) et dans les Mascareignes où les colons ont refusé la liberté générale, sans le rétablir à Saint-Domingue, en Guadeloupe et en Guyane. 

l'expédition se traduit par l'indépendance sous le nom d'Haïti, le $1^{\mathrm{er}}$ janvier 1804. L'expédition de Richepance se solde par la mort ou la déportation de tous les militaires de couleur de Guadeloupe. La répression y fait de 3 à 4000 morts et autant de déportés, de mai à décembre $1802^{156}$. Le 17 juillet 1802, l'arrêté pris par Richepance, supprime aux gens de couleur le titre de citoyen qu'ils avaient obtenu depuis la loi du 4 avril 1792. Richepance justifie cette mesure en affirmant que seuls les blancs sont « indigènes de la nation française.» C'est l'argument du sang qui est utilisé pour écarter les libres de couleur de la citoyenneté. Etant descendant d'Africains, ils ne peuvent être citoyens. Cet arrêté écarte de la garde nationale les libres de couleur. Ces derniers doivent rendre ou vendre leurs armes. La mesure supprime les administrations municipales ce qui permet d'en écarter les hommes de couleur qui en faisaient partie. Les cultivateurs sont assignés à leur ancienne propriété. Cette dernière disposition existait déjà dans les règlements de culture. Le fait le plus nouveau est la suppression du quart de revenus qui revenait aux cultivateurs. Il est également donné la possibilité aux anciens maîtres de les enchaîner, de les mettre au cachot et de les «soumettre à la discipline correctionnelle» (vraisemblablement le fouet) ${ }^{157}$. Cette suppression de la citoyenneté devait certainement faire partie des instructions données à Richepance par le gouvernement consulaire. En effet, il est difficilement imaginable que le général ait pris cette décision de son propre chef. Cette suppression de la citoyenneté des hommes de couleur et le retour à des pratiques esclavagistes précèdent d'un an, le rétablissement officiel de l'esclavage. En effet, si dès le 16 juillet 1802, Napoléon Bonaparte rétablit l'esclavage en Guadeloupe ${ }^{158}$, c'est, un an plus tard, en mai 1803, que la décision y est officiellement proclamée.

En Guyane, l'autorité du gouvernement consulaire a été maintenue par Victor Hugues, arrivé en 1800. Il a mis en place un sévère règlement de culture et les cultivateurs restent calmes. Le 7 décembre 1802, Napoléon Bonaparte met en place un système dualiste en Guyane. Ceux qui y étaient esclaves au jour de la proclamation de la liberté générale, le 14 juin 1794, deviennent des conscrits de quartier. Ils sont attachés à une plantation ou une propriété et ne peuvent plus être vendus de gré à gré. Cela s'apparente au servage. Quant aux noirs et hommes de couleur qui sont arrivés en Guyane, depuis le 14 juin 1794, soit par l'effet de capture de navires négriers, soit depuis le rétablissement de la traite par la loi du 20 mai 1802, ils sont esclaves ${ }^{159}$. Les décisions prises concernant la Guyane semblent corroborer l'idée que Bonaparte n'a pas de plan préétabli de rétablissement complet de l'esclavage lorsqu'il envoie les expéditions Leclerc et Richepance. En effet, en Guyane, où il peut le rétablir facilement, il choisit une forme de servage, Le 29 mai 1803, comme l'y incite Decrès, ministre de la marine et des colonies, Victor Hugues supprime la catégorie des conscrits de quartier et l'intègre dans celle des esclaves. Il donne la possibilité à leur propriétaire de vendre les conscrits de quartier à partir du 20 juin 1804 ${ }^{160}$. Par ce biais, Victor Hugues rétablit complètement l'esclavage.

Dans les colonies, les droits politiques du citoyen et l'accès au droit de participer à la puissance publique ont été remis en cause par les régimes autoritaires de Napoléon Bonaparte et de Toussaint Louverture. La citoyenneté est supprimée pour les hommes de couleur dans toutes les colonies restées françaises, sauf à Haïti, où à l'inverse, il ne peut exister de citoyens blancs ${ }^{161}$. La suppression de la citoyenneté pour les hommes de couleur rendus citoyens par la loi du 4 avril 1792, s'effectue pour la Guadeloupe par l'arrêté de Richepance du 17 juillet 1802. Dans les autres colonies, c'est par le biais des différentes promulgations du code civil en 1805, qu'ait rétabli le préjugé de couleur 
entraînant la mise à l'exclusion de la citoyenneté les hommes de couleur. Le Code civil s'applique dans le respect de la classification juridique tripartite de la population des colonies. Les dispositions du Code ne s'appliquent aux blancs entre eux, aux libres de couleurs entre eux, mais pas entre blancs et libres de couleur et pas du tout aux esclaves 162 .

\section{Le rétablissement de la citoyenneté des hommes de couleur}

86 A la suite de la Révolution de 1830 et de la mobilisation des libres de couleur ${ }^{163}$, ces derniers redeviennent citoyens par la loi du 24 avril 1833. Elle supprime toutes les « restrictions et exclusions qui avaient été prononcées, quant à l'exercice des droits civils et des droits politiques, à l'égard des hommes de couleur libres et des affranchis » et dispose que toute personne née libre ou légalement affranchie jouit, dans les colonies françaises, des droits civils et des droits politiques. Toutefois, la loi électorale votée le même jour écarte de fait la plupart des libres de couleur de la vie politique. Le montant de l'impôt qu'il faut payer pour être électeur est de 300 francs, 600 pour être éligible, dans les colonies alors qu'il est de 200 et 500 francs, en métropole. Lors des élections de 1834 en Martinique, seulement $3 \%$ des électeurs sont des hommes de couleur. De ce fait, il faut attendre 1845, pour voir le premier élu de couleur au conseil colonial de la Martinique. En 1847 , les hommes de couleur représentent $10,3 \%$ des électeurs et 5,7\% des éligibles en Guadeloupe ${ }^{164}$, alors qu'ils sont trois fois plus nombreux que les blancs. En effet, sous la Monarchie de Juillet, les affranchissements sont facilités et le nombre des esclaves affranchis a considérablement augmenté. A la veille de l'abolition, plus d'un tiers de la population est libre dans les colonies esclavagistes, mais seule une minorité jouit des droits d'électeurs.

Tableau 2. Population libre et esclave dans les colonies françaises à la veille de l'abolition

\begin{tabular}{|l|l|l|l|}
\hline & $\begin{array}{l}\text { Nombre d'esclaves au } \\
\text { moment } \\
\text { l'abolition }\end{array}$ & $\begin{array}{l}\text { Population totale (selon } \\
\text { le recensement de 1847) }\end{array}$ & $\begin{array}{l}\text { Proportion de libres (blancs et } \\
\text { de couleur) par rapport à la } \\
\text { population totale }\end{array}$ \\
\hline Guadeloupe & 87087 & 129050 & $33 \%$ \\
\hline Guyane & 12525 & 18914 & $34 \%$ \\
\hline Martinique & 74447 & 120357 & $38 \%$ \\
\hline La Réunion & 60651 & 103490 & $41 \%$ \\
\hline
\end{tabular}

En 1848, à la suite d'une nouvelle révolution, l'esclavage est à nouveau aboli. Selon Yerri Urban, dans la rédaction originelle, il était prévu une disposition dans le décret d'abolition du 27 avril 1848 dans laquelle "Tout affranchi devient citoyen français. » Toutefois, la commission chargée de préparer l'abolition estime que cela aboutirait en Algérie « à rendre citoyen les maîtres arabes, qui eux-mêmes ne sont pas citoyens. » C'est donc par le biais de la loi du 24 avril 1833 instaurant l'égalité juridique entre libres de 
couleur et blancs que les anciens affranchis et les natifs libres des établissements français de l'Inde et des comptoirs du Sénégal se verront reconnaître la citoyenneté ${ }^{165}$.

La question de la citoyenneté dans des colonies marquées par le préjugé de couleur, l'esclavage et l'Exclusif, s'invite dans les débats des assemblées révolutionnaires. L'Assemblée constituante, en plaçant les colonies hors du champ d'application de la constitution et en laissant une large autonomie aux assemblées coloniales, pense éviter de traiter l'écueil de la compatibilité entre les principes de la Déclaration des droits de l'homme et du citoyen avec l'esclavage et le préjugé de couleur. La mobilisation d'un groupe de gens de couleur à Paris, l'action des philanthropes de la Société des Amis des Noirs et les révoltes dans les colonies vont amener les assemblées à proclamer l'égalité de tous les libres, le 15 mai 1791 (pour seulement ceux nés libres), et le 28 mars 1792 (décret sanctionné par le roi, le 4 avril). Le contexte général de l'armement des esclaves, dans le cadre d'une guerre à la fois civile et internationale, en présence de commissaires civils philanthropes, aboutit à l'octroi de la citoyenneté des esclaves, le 4 février 1794. Ce sont surtout les développements coloniaux de la Révolution qui expliquent les mesures prises.

La Première République, en raison de son éloignement, de sa faible durée et de ses difficultés mêmes en métropole, n'a pas réussi à répondre au défi posé par la citoyenneté des hommes de couleur. Elle s'est montrée à cours d'idées pour régénérer le système colonial. La seule réponse aux défis posés à la Révolution est la militarisation de la population de couleur qui tient en elle, les germes de la limitation ou de la suppression de la citoyenneté. Cette militarisation est forte à Saint-Domingue, moyenne en Guadeloupe et faible en Guyane. Ces différences expliquent les destins différents de leurs populations. Haïti doit donc son indépendance à la très forte militarisation de sa population de couleur, avec pour effet la caporalisation du peuple à l'origine d'une liberté n'impliquant qu'une participation réduite à la vie de la cité. En Guadeloupe, c'est d'abord la citoyenneté des hommes de couleur qui est supprimée, le 17 juillet 1792. La plupart des citoyens sont alors des notables ou des soldats de couleur. Les premiers sont réduits à leur situation avant la loi du 4 avril 1792, les seconds sont déportés ou tués. En Guyane, où il n'y a quasiment pas eu de recrutements de soldats de couleur dans une colonie très peu peuplée, des règlements de culture sévères sont remis en place, sans révolte ouverte.

Dans les années 1820, les libres de couleur de la Martinique, puis de la Guadeloupe se mobilisent pour retrouver la citoyenneté qu'ils finissent par obtenir, le 24 avril 1833. Le combat de certains citoyens de couleur comme Cyrille Bissette ${ }^{166}$ qui après s'être battus pour leurs droits se battent pour l'abolition de l'esclavage est un facteur qui a favorisé l'octroi de la citoyenneté aux esclaves en 1848. Par ce combat aux côtés des Républicains, ils montrent que les affranchis des anciennes colonies esclavagistes sont dignes de la citoyenneté.

91 La période de la Révolution française a permis aux hommes de couleur de devenir citoyens. C'est cet héritage révolutionnaire qui favorise la réadmission dans la citoyenneté des libres de couleur à l'issue de la Révolution de 1830, puis des esclaves à l'issue de celle de 1848. A l'inverse, les esclaves de l'Algérie qui pourtant bénéficient de l'abolition de 1848, ne deviennent pas citoyens. Ce choix d'une liberté sans citoyenneté sera étendu à toutes les nouvelles conquêtes coloniales de la seconde moitié du XIX ${ }^{e}$ siècle 


\section{NOTES}

1. Source : http://www.slavevoyages.org, Base de données coordonnée par David Eltis, consultée le 10 décembre 2011.

2. Interview de Vertus Saint-Louis du 9 janvier 2010. http://www.frantzfanoninternational.org/ spip.php?article211 (consulté le 30 décembre 2011).

3. Frédéric RÉGENT, La France et ses esclaves, de la colonisation aux abolitions, 1620-1848, Paris, Grasset, 2007 (rééd. Fayard-Pluriel, 2012), p. 57-64. ; Frédéric RÉGENT, « La fabrication des Blancs dans les colonies françaises », dans Sylvie Laurent, Thierry Leclère (dir.), De quelle couleur sont les Blancs?, Paris, La Découverte, 2013, p. 67-75 ; Frédéric RÉGENT, «Le métissage des premières générations de colons en Guadeloupe et à l'île Bourbon (Réunion)», dans Guy Brunet (dir.), Mariage et métissage dans les sociétés coloniales, Amériques, Afrique et îles de l'Océan Indien (XVI ${ }^{e}-\mathrm{XX}^{e}$ siècles), Berne, Peter Lang, 2015, p. 111-131.

4. Félix LonGIN, Voyage à la Guadeloupe, œuvre posthume (1818-1820), Le Mans, Monnoyer, 1848, p. 48.

5. Les «blancs creoles» sont nés dans les colonies et ont la réputation d'avoir une ascendance formée uniquement d'Européens. Les « blancs » nés en Europe paient comme les libres de couleur la capitation.

6. En 1789 paraît à Londres, un ouvrage intitulé Observations sur le préjugé de la noblesse héréditaire. Son auteur, Nicolas Bergasse (1750-1832) est également membre de la société des Amis des Noirs. Il est député aux Etats Généraux. Dans ce pamphlet, l'auteur réclame la destruction du préjugé de noblesse, c'est-à-dire la fin des privilèges de la noblesse.

7. Yann-Arzel DURELLE-MARC, «Sur la question coloniale durant la Constituante (1789-1791): l'idéal libéral à l'épreuve des colonies », dans Frédéric Régent, Jean-François NIORT, Pierre SERNA (dir.), Les colonies, la Révolution française, la loi, Rennes, PUR, 2014, p. 63.

8. Charles Frostin, Les Révoltes blanches à Saint-Domingue aux XVII et XVIII ${ }^{e}$ siècles. Paris, L'Ecole, 1975.

9. Déborah LIÉBART, «Un groupe de pression contre-révolutionnaire: le club Massiac sous la constituante ", Annales historiques de la Révolution française, $n^{\circ} 354,2008$, p. 31.

10. Les plus grandes plantations sont celles qui produisent du sucre. Elles ont une main-d'œuvre composée de plus d'une centaine d'esclaves la plupart du temps.

11. Vertus SAINT-Louis, Mer et liberté, Haïti (1492-1794), Port-au-Prince, FOKAL, 2008, p. 365-368.

12. Moreau de Saint-Méry est le plus important compilateur des lois des colonies. Il avait pour projet d'écrire une encyclopédie colonial. Il laisse aux historiens l'importante documentation qu'il a rassemblée pour y parvenir. Ces documents sont rassemblés dans la collection et dans la bibliothèque Moreau de Saint-Méry conservée aux Archives Nationales d'Outre-Mer.

13. ANOM, Bibliothèque Moreau de Saint-Méry (désormais BMS), série 1, vol. 9.

14. Gouy d'ARsy, Confession d'un député dans ses derniers moments ou liste des péchés de Louis-Marthe de Gouy-d'Arsy, Paris, Chez Demonville, 1791.

15. BNF, Lb39-1643. Mémoire sur l'importance pour la colonie de Saint-Domingue, d'avoir des représentants à l'assemblée des États généraux, et sur la forme la plus légale de procéder à l'élection de ses députés, Paris, Clousier, 28 septembre 1788, 12 p. Ce mémoire est signé des 9 commissaires du comité colonial : le duc de Cereste-Brancas, le duc de Choiseul-Praslin, le comte de Magallon, le comte de Reynaud, le comte de Peyrac, le marquis de Perrigny, le marquis de Paroy, le chevalier 
de Dougé et le marquis de Gouy d'Arsy. Ce dernier est le commissaire rapporteur du conseil, ainsi formé.

16. Ibid, p. 10.

17. Vertus SAINT-LOUIS, op. cit., p. 99

18. Ibid, p. 100.

19. Yann-Arzel DURELLE-MARC, op. cit., p. 56.

20. Collection Baudouin, vol 1, Arrêté concernant la Députation de Saint-Domingue, 4 Juillet 1789.

21. Gabriel DEBIEN, Les colons de Saint-Domingue et la Révolution. Essai sur le club Massiac (août 1789août 1792), Paris, A. Colin, 1953.

22. Manuel Covo, «L'Assemblée constituante face à l'Exclusif colonial », dans Frédéric Régent, Jean-François Niort et Pierre Serna (dir.), op. cit., p. 76-78.

23. Déborah LIÉBART, op. cit., p. 32-33.

24. Manuel Covo, «L'Assemblée constituante... », op. cit., p. 76

25. Yann-Arzel DuRELLE-MARC, op. cit., p. 58.

26. Yves BENOT, La Révolution française et la fin des colonies, Paris, La Découverte, 1989, p. 49.

27. John GARRIGUS, A Struggle for Respect: The free Coloreds of Saint-Domingue, 1760-1769, Baltimore, Johns Hopkins University Press, 1988, p. 195 ; Stewart KING, Blue coat or powered wig, free people of colour in prerevolutionnary Saint-Domingue, University of Georgia Press, 2001, p. 117.

28. Frédéric RÉGENT, Esclavage, métissage, liberté. La Révolution française en Guadeloupe (1789-1802), Paris, Grasset, 2004.

29. John GARRIGUS, "Colour, Class and Identity on the Eve of the Haitian Revolution: SaintDomingue's Free Coloured Elite as Colons américains ", Slavery and Abolition, vol. 17, avril 1996, p. 23-24. Les trois quartiers étudiés sont Cayes, Saint-Louis et Aquin.

30. Frédéric RÉGENT, La France et ses esclaves, de la colonisation aux abolitions, 1620-1848, Paris, Grasset, 2007, p. 209.

31. ANOM, F3 133, « Notes historiques sur Saint-Domingue », p. 133. Selon Moreau de Saint-Méry, les libres de couleur de la Martinique sont plus insolents que ceux de la Guadeloupe, ce qui signifie aussi plus opulents.

32. Claude WANQUET, « La perception des problèmes de couleur dans les Mascareignes pendant la Révolution et le syndrome dominguois ", dans Michel Hector (dir.), La Révolution française et Haïti. Filiations, ruptures, nouvelles dimensions, Port-au-Prince, Société Haïtienne d'histoire et de géographie et Editions Henri Deschamps, 1995, tome II, p. 244, 281.

33. Julien Raimond est un quarteron libre de Saint-Domingue.

34. Marcel DoRignY, Bernard GAINOT, La Société des Amis des Noirs (1788-1799), Contribution à l'histoire de l'abolition de l'esclavage, Ed. Unesco, 1998, p. 244.

35. A Saint-Domingue, un individu qui a trois grands parents blancs et un noir est qualifié de quarteron.

36. Pierre Boulle, «Les gens de couleur à Paris à la veille de la Révolution », dans Michel Vovelle (dir.), L'image de la Révolution française, Actes du Congrès mondial pour le bicentenaire, Paris-Sorbonne, 6-12 juillet 1989, Oxford, Pergamon Press, 1990, p. 159-168. D'après les recensements effectués entre 1777 et 1790, l'auteur relève 765 déclarations de gens de couleur à Paris.

37. ANOM, F3-91, Fol. 224.

38. Yves BENOT. op. cit., p. 71-72.

39. ANOM, BMS, 1 ère série, volume 20 , pièce 16 , «Lettre des citoyens de couleur des Isles et colonies Françoises ; à MM. Les Membres du Comité de Vérification à l'Assemblée Nationale du 23 novembre 1789 ».

40. Laurent DuBoIs, Avengers of the New World: The Story of the Haitian Revolution, Cambridge, Harvard University Press, 2004, p. 21.

41. Florence GAUTHIER, L'aristocratie de l'épiderme, Paris, CNRS, 2007, p. 47. 
42. Abbé GRÉGOIRE, Mémoire en faveur des gens de couleur, Paris, 1789 ; publié dans La Révolution française et l'abolition de l'esclavage, Paris, EDHIS, 1968, t. I.

43. ANOM, ADXVIIIc 118, $\mathrm{n}^{\circ} 21$, "Observations d'un habitant des colonies sur le Mémoire en faveur de Gens de couleur ou Sang-mêlés », s. 1., 16 décembre 1789.

44. Yann-Arzel DURELLE-MARC, op. cit., p. 59.

45. Ibid, p. 61.

46. Sur la formation du Comité et pour des renvois historiographiques plus précis, voir Manuel covo, « Le Comité des colonies : une institution au service de la famille coloniale ? ", La Révolution française, revue en ligne, $n^{\circ}$ 3, 2012.

47. Les assemblées coloniales de la Guadeloupe et de la Martinique se réunissent depuis 1787.

48. ANOM, BMS, 1ère série volume 25 , pièce 28 , « Réclamation des citoyens de couleur des Isles et colonies françoises sur le décret du 8 mars 1790, Paris, 10 mars 1790 ».

49. Yves BENOT, op. cit., p. 72-73.

50. Déborah LIÉBART, op. cit., p. 36.

51. ANOM, $C^{8 \mathrm{~A}} 89-1789$, Faits dont $M$. le comte de Vioménil est accusé, puisés dans les rapports et mémoires remis au Comité de Saint-Pierre..., (sans date), folios $98 \mathrm{v}^{\circ}-100 \mathrm{v}^{\circ}$, cité par Abel LouIS, Les libres de couleur en Martinique, des origines à 1815, l'entre deux d'un groupe social dans la tourmente coloniale, thèse d'histoire sous la direction de Danielle Bégot, Université des Antilles et de la Guyane, 2010, tome 1, p. 389-390.

52. Exposé de la conduite des gens de couleur du Fort-Royal, daté de 1789, cité par Léo ELISABETH, « La République dans les Iles du Vent ", Révolutions aux colonies, Publication des AHRF, 1993, p. 44.

53. Abel LouIs, op. cit., p. 389-390.

54. ANOM, $\mathrm{C}^{8 \mathrm{~A}} 89$, "Ordonnance de MM. Vioménil et Foullon d'Écotier, portant convocation d'une assemblée générale de la colonie (22 octobre 1789) », fo 48-49, cité par Abel Louis, op. cit., p. 389-390.

55. Abel Louis, op. cit., p. 394.

56. Dimitri TномAs, Les gouverneurs de la Martinique à l'épreuve de la Révolution française (1789-1792), mémoire de Master 1 sous la direction de Frédéric Régent, Université Paris 1 Panthéon-Sorbonne, 2013, p. 69.

57. Pierre-François-Régis DesSALLEs (1755-1808), Historique des troubles survenus à la Martinique pendant la Révolution, Fort-de-France, Société d'histoire de la Martinique, 1982, p. 68-69.

58. Dimitri THомAs, op. cit. , p. 70.

59. ANOM, $C^{8 \mathrm{~A}} 94$, «Lettre de Foullon d'Écotier, intendant, au ministre de la marine et des colonies (Saint-Pierre, le 26 mai 1790) », f० 222, cité par Abel LouIs, op. cit., p. 408.

60. Léo ElisABETH, op. cit., p. 88.

61. Pierre-François-Régis DESSALLES (1755-1808), Historique des troubles survenus à la Martinique pendant la Révolution, Fort-de-France, Société d'histoire de la Martinique, 1982, p. 198-199.

62. Ibidem.

63. Abel Louis, op. cit., p. 40-41.

64. Jean-Philippe GARRAN DE COULON, Rapport sur les troubles de Saint-Domingue, fait au nom de la Commission des colonies, des Comités de salut public, de législation et de marine, réunis, Paris, Imprimerie Nationale, 1797, t. I, p. 110.

65. Pour le détail de la politique défendue par Saint-Marc, voir Martine Kahane, La première assemblée coloniale révolutionnaire à Saint-Domingue: l'assemblée de Saint-Marc, thèse, Ecole des Chartes, 1970.

66. Robin BLACKBURN, The Overthrow of Colonial Slavery (1776-1848), Brooklyn-London,Verso, 1988, p. 183.

67. Les assemblées provinciales du Nord, de l'Ouest et du Sud se réunissent pour la première fois, respectivement, le $1^{\text {er }}$ novembre 1789, en janvier 1790 et le 15 février 1790. 
68. Manuel Covo, Commerce, empire et révolutions dans le monde atlantique La colonie française de Saint-Domingue entre métropole et États-Unis (ca. 1778 - ca. 1804), thèse sous la direction de François Weil, EHESS, 2013, p. 179.

69. Oliver Gliech, Saint-Domingue und die Französische Revolution: Das Ende der weissen Herrschaft in einer karibischen Plantagenwirtschaft, Cologne-Weimar-Vienne, Böhlau Verlag, 2011, p.

70. Manuel Covo, op. cit., p. 180.

71. Jacques ADÉLAÏDE-MERLANDE, La Caraibe et la Guyane au temps de la Révolution et de l'Empire, Paris, Karthala, 1992, p. 34-37.

72. Frédéric RÉGENT, Esclavage, métissage, liberté..., op. cit., p. 225-229.

73. Claude W ANQUET, Histoire d'une Révolution, la Réunion (1789-1803), Marseille, Jeanne Laffitte Editions, 1980, tome I, p. 268, 281.

74. Musleem JumeER, Les affranchis et les Indiens libres à l'île de France au XVIIIe siècle (1721-1803), thèse de doctorat de $3^{\mathrm{e}}$ cycle, Université de Poitiers, 1984, p. 174-180.

75. Ce document intitulé « Très humbles doléances et remontrances des habitans du Sénégal aux citoyens français tenant les États Généraux » a été publié pour la première fois dans Dominique L AMIRAL, L'Affrique et le peuple affriquain considérés sous tous leurs rapports avec notre commerce et nos colonies, Paris, Dessenne, 1789, IV-400 p.

76. Yves BÉNOT, La Guyane sous la Révolution, Matoury, Ibis Rouge, 1997, p. 54-55 : 812 Amérindiens sont recensés en Guyane en 1789. Il s'agit de ceux qui vivent dans les zones colonisées par les Français.

77. ANOM BMS, $1^{\text {ère }}$ série volume 124 , pièce 6 , Pétition nouvelle des citoyens de couleur des îles françoises à l'assemblée nationale, Paris, Chez Desenne, Bailly et au bureau du Patriote François, 18 mars 1791, XII, p. 19.

78. Yves BENOT, La Révolution et la fin des colonies..., op. cit., p. 79. Selon Yves Bénot, Robespierre est encore faible à l'époque. Son discours n'exprime pas sa conviction intime, il sait très bien que le rapport de force à ce moment rend impossible une liberté générale pour les esclaves, et que le seul moyen de dégager une majorité pour obtenir l'égalité de traitement pour les libres de couleur, est de faire comprendre aux députés hésitants que la mesure ne compromet pas l'ordre social.

79. ANOM BMS, 1 ère série volume 31 , pièce 14 , Julien RAIMOND, Réponse aux considérations de M Moreau dit Saint-Méry député à l'assemblée nationale sur les colonies par M. Raymond, citoyen de couleur de Saint-Domingue, 12 mai 1791.

80. ANOM BMS, $1^{\text {ère }}$ série volume 33, pièce 9, Extrait du décret du 13 mai 1791.

81. Le Moniteur, $\mathrm{n}^{\circ}$ 138, 18 mai 1791, Paris, Plon, 1858 (rééd.), p. 418.

82. Manuel Covo, op. cit., p. 201.

83. Laurent DuBoIs, op. cit., p. 119-120.

84. ANOM BMS, $1^{\text {ère }}$ série volume 41 , pièce 20 , Pierre MONNERON, Observations sur une lettre de M. Moreau de Saint-Méry écrite le 3 septembre 1791, Paris, imprimerie du Patriote Français, 23 septembre $1791,8 \mathrm{p}$.

85. ANOM BMS, $1^{\text {ère }}$ série volume 33 , pièce 19 , Jean-Pierre BRISSOT, Discours sur la nécessité de maintenir le décret rendu le 15 mai 1791, en faveur des hommes de couleur libres, prononcé le 12 septembre 1791, à la séance de la Société des Amis de la Constitution, séante aux Jacobins, Paris, Société des Jacobins, $28 \mathrm{p}$.

86. BNF, LK12-946, Adresse à l'Assemblée nationale par les hommes de couleur libres de SaintDomingue, s.l., 1791, p. 83-84. Cet ouvrage contient un document intitulé «A Messieurs de l'Assemblée générale de la partie française de Saint-Domingue, séant à Saint-Marc ", qui commence à la page 20. L'ouvrage cite Idées sommaires sur quelques règlements à faire par l'Assemblée coloniale; par M. le baron de Beauvois, conseiller au Conseil-supérieur du Cap, correspondant de 
l'Académie Royale des Sciences, ci-devant associé de la Société Royale des Sciences \& Arts de Saint-Domingue, Cap-Français, Batilliot, 1790

87. Thomas MADIOU, Histoire d'Haïti, Port-au-Prince, Impr. Courtois, 1847, tome 1 p. 61.

88. Archives départemantales de la Guadeloupe (désormais ADG), 1B 12, Conseil souverain de Guadeloupe. Requête présentée, par Jean-Baptiste Caniquit, habitant au quartier du Moule, et Pierre Chauvel mari d'Elizabeth Caniquit, habitant au Morne-à-l'Eau, le 19 janvier 1791.

89. ADG, 1B 12, Conseil souverain de Guadeloupe. Arrêté du 10 janvier 1791 en faveur du sieur Antoine Aurange.

90. Claude WANQUET, op. cit., tome I, p. 392-393.

91. Jean-Pierre BRISSOT, Discours sur les troubles de Saint-Domingue, Paris, $1^{\mathrm{er}}$ décembre 1791, p. 7-8 (cité par Marcel DoRIGNY, "La société des amis des noirs, les Girondins et la question coloniale », dans Collectif, Esclavage, colonisation, libérations nationales, Paris, L'Harmattan, 1990, p. 70).

92. Laurent DuBoIs, op. cit., p. 122, 136.

93. François BlancPaIn, Etienne de Polvérel, libérateur des esclaves de Saint-Domingue, Becherel, Les Perséides, 2010, p. 74.

94. François BlANCPAIN, op. cit., p. 74.

95. Marcel DORIGNY (dir.), Léger-Félicité Sonthonax. La première abolition de l'esclavage. La Révolution française et la Révolution de Saint-Domingue, Paris, APECE et Société française d'Histoire d'Outremer, 1997; Robert STEIN. Léger Félicité Sonthonax: The Lost Sentinel of the Republic, London, Associated University Presses, 1985.

96. Pour plus détails sur la vie de Polverel, voir François BLANCPAIN, op. cit.

97. François BLANCPAIN, op. cit., p. 77.

98. Ibid., p. 72-73.

99. Il fut établi une liste des citoyens blancs et de couleur ayant 25 ans accomplis, propriétaires d'immeubles ou contribuables par les officiers municipaux, la semaine précédant le scrutin. Pour y être inscrits, les libres de couleur devaient justifier de leur liberté par des titres légaux. Frédéric RÉGENT, Esclavage, métissage, liberté..., op. cit., p. 232.

100. Abel Louis, op. cit., p. 432-433.

101. $\mathrm{AN}, \mathrm{C} 8 \mathrm{~A} / 99, \mathrm{f}^{\circ}$ 79-80, Lettre du commandant de Saint-Pierre, de Mollerat, à de Behague, Saint-Pierre, le 17 août 1792, cité par Abel Louis, op. cit., p. 432.

102. "Journal de Pierre Philippe Lecourt (septembre 1792-mars 1794)", Annales des Antilles, Bulletin de la Société d'Histoire de la Martinique, 1994, n² 29, p. 66-67.

103. Frédéric RÉGENT, «Devenir Républicain aux Petites Antilles (Guadeloupe, Martinique) à travers l'exemple de l'élection des députés à la Convention», dans Michel Biard, Philippe Bourdin, Hervé Leuwers, Pierre Serna (dir.), 1792. Entrer en République, Armand Colin, 2013, p. 152

104. $\mathrm{AN}, \mathrm{AD}$ XVIIIC $336, \mathrm{n}^{\circ} 24$. Rapport sur la validité de l'élection des députés de la Guadeloupe et de la Martinique le 28 octobre 1792.

105. Lanrent DuboIs, Les esclaves de la République, Paris, Calmann-Lévy, 1998, p. 108 et 221.

106. AN, C181, 86, Procès-verbal de nomination des députés et des suppléans à la Martinique et à la Guadeloupe à la Convention Nationale, 28 octobre 1792.

107. ANOM, C8A 102, fol. 137, Adresse des citoyens de couleur de la Martinique à l'Assemblée coloniale, 9 janvier 1793.

108. Tous ces aspects sont développés dans le chapitre IV de Frédéric RÉGENT, Esclavage, métissage, liberté..., op. cit.

109. Abel Louis, op. cit., p. 468.

110. Le Patriote français, $\mathrm{n}^{\circ} 1264,26$ janvier 1793.

111. Jean-Daniel PIQUET, L'émancipation des Noirs dans la pensée et le processus révolutionnaire français (1789-1795), doctorat d'histoire, Paris-VIII, 1998, 736 p. thèse éditée sous le titre L'émancipation des 
Noirs dans la Révolution française (1789-1795), Paris, Karthala, 2002, p. 259. Pour tous ces débats, voir cet ouvrage.

112. Denis SIEGER, La presse et l'insurrection des esclaves de Saint-Domingue octobre 1791-avril 1792, mémoire de Master sous la direction de Bernard Gainot, Université Paris 1-Panthéon-Sorbonne, 2010.

113. AN, DXXV 20, cité par François BLANCPAIN, op. cit., p. 96-97.

114. Jeremy POPKIN, You are all free: the haitian revolution and the abolition of slavery, Cambridge, Cambridge University Press, 2010, p. 188-245.

115. ANOM, F 3 198, Proclamation de 11 juillet 1793, version créole.

116. François BLANCPAIN, op. cit., p. 141-150.

117. AN, D XXV 13, Proclamation de 29 août 1793.

118. François BLANCPAIN, op. cit., p. 144 et 153.

119. Le commandeur est l'esclave qui tient le fouet et encadre le travail des cultivateurs.

120. François BlanCPAIN, op. cit., p. 154.

121. David GEGGUS, Slavery, war and revolution: the British occupation of Saint-Domingue, 1793-1798, Oxford, Clarendon Press, 1982.

122. AN, AA55, d. 1511. Réponse sentimentale pour servir au sujet de la lettre sur la révolution de St. Domingue, Jeudy. 8 aoust 1793, signée de Toussaint-Louverture.

123. AN, DXXV 44. Lettre de Sonthonax à Polverel, 27 octobre 1793.

124. Pierre SERnA, «Que s'est-il dit à la Convention les 15,16 et 17 pluviôse an II ? Ou lorsque la naissance de la citoyenneté universelle provoque l'invention du «crime de lèse-humanité » », La Révolution française [enline], 7 | 2014, Consulté le 2 mai 2015. URL : http://lrf.revues.org/1208.

125. David GegGuS, «From his Most Catholic Majesty to the Godless Republic: The Volte-Face of Toussaint Louverture and the Ending of Slavery in Saint-Domingue ", Revue française d'histoire d'Outre-mer, $n^{\circ} 65,1978$, p. 481-499.

126. Frédéric RÉGENT, «From individual to Collective Emancipation : War and the Republic in the Caribbean during the French Revolution", dans Pierre Serna, Antonino de Francesco, Judith Miller (dir.), Republics at War (1776-1840), New York, Palgrave-Macmillan, 2013, p. 165-186.

127. Art. 7. «Elles sont divisées en départements, ainsi qu'il suit ; - L'île de Saint-Domingue, dont le Corps législatif déterminera la division en quatre départements au moins, et en six au plus ; La Guadeloupe, Marie-Galante, la Désirade, les Saintes, et la partie française de Saint-Martin ; - La Martinique ; - La Guyane française et Cayenne ; - Sainte-Lucie et Tabago ; - L'île de France, les Séchelles, Rodrigue, et les établissements de Madagascar ; - L'île de la Réunion ; - Les IndesOrientales, Pondichéry, Chandernagor, Mahé, Karical et autres établissements. »

128. Didier Destouches, Du statut colonial au statut départemental. L'administration révolutionnaire en Guadeloupe (1787-AnX), Aix-en-Provence, PUAM - Société française de publication de textes en histoire juridique, 2007, coll. d'Histoire du droit.

129. Bernard GAINOT, «La naissance des départements d'outre-mer. La loi du $1^{\mathrm{er}}$ janvier 1798 », Revue des Mascareignes, $\mathrm{n}^{\circ}$ 1, 1999, p. 51-74.

130. ANOM BMS, $1^{\text {ère }}$ série, volume 51 , pièce 4 . Loi du 12 nivôse an VI ( $1^{\text {er }}$ janvier 1798).

131. Yerri URBAN, "La citoyenneté en Haïti, des départements coloniaux aux premières constitutions", $3^{\mathrm{e}}$ rencontres du grand séminaire d'histoire d'outre-mer, 9 avril 2015, communication non publiée. Voir du même auteur, Yerri URBAN, «La citoyenneté dans l'empire colonial français est-elle spécifique? », Jus Politicum n 14, juin 2015, http://juspoliticum.com/Lacitoyennete-dans-l-empire.html.

132. Eric DE MARI, « Notes sur le droit privé dans la pratique notariale à l'Ouest et au Sud de SaintDomingue de l'an II à l'an V III [1793-1800] », dans Frédéric Régent, Jean-François Niort, Pierre Serna (dir.), op. cit., p. 107-123.

133. François BlanCPAin, op. cit., p. 227. 
134. ANOM, C7A 49, fol. 226-227, Lettre des agents au ministre, Basse-Terre, le 4 brumaire an VI (25 octobre 1797).

135. Ibid., fol. 20-27.

136. AN, AD XVIII a (56), Opinion de Pinchinat, cite dans Bernard Gainot, «La députation de Saint-Domingue au corps législatif du Directoire ", Revue française d'Histoire d'Outre-Mer (Paris), 1997, t. 84, nº 316, p. 95-110.

137. Bernard GAINOT, « La députation de Saint-Domingue au corps législatif du Directoire », Revue française d'Histoire d'Outre-Mer (Paris), 1997, t. 84, n³16, p. 95-110

138. AN, C513, pièce 99, procès-verbal de l'assemblée électorale de Saint-Domingue, tenue au Cap le 20 germinal an $\mathrm{V}$ (9 avril 1797).

139. Frédéric RÉGENT, « Droit et pratique de la liberté générale en Guadeloupe (1794-1802) », dans Frédéric Régent, Jean-François Niort et Pierre Serna (dir.), op. cit., p. 137-138.

140. Jean-François N IORT, Jérémy RICHARD, «De la Constitution de l'an V III [1799] au rétablissement de l'esclavage (1802) et à l'application du Code civil dans les colonies françaises (1805) : le retour d'un droit colonial réactionnaire sous le régime napoléonien », dans Frédéric Régent, Jean-François Niort, Pierre Serna (dir.), op. cit. p. 168.

141. Euvres de Napoléon Bonaparte, Panckoucke, 1821, tome III. Lettre du Premier Consul Bonaparte aux citoyens de Saint-Domingue, daté de Paris, le 4 nivôse an VIII (25 décembre 1799).

142. Bernard GAINOT, «La naissance des départements d'outre-mer. La loi du $1^{\mathrm{er}}$ janvier 1798 ", Revue d'histoire des Mascareignes, 1, 1998, numéro spécial, p. 51-75.

143. Frédéric CHARLIN, «L'expérimentation de l'identité législative aux colonies, de la Convention au Directoire ", dans Frédéric Régent, Jean-François Niort, Pierre Serna (dir.), op. cit., p. 93-106.

144. Pierre-Louis RoEDERER, CEuvres, Paris, 1856, p. 334 cité dans Mathieu Brevet, Les Expéditions coloniales vers Saint-Domingue et les Antilles (1802-1810), thèse d'histoire, Université Lyon 2, p. 9.

145. François BLANCPAin, op. cit., p. 191.

146. Jacques ADÉLAÏDE-MERLANDE, Delgrès. La Guadeloupe en 1802, Paris, Karthala, 1986, p. 49.

147. ANOM, C7A 82 pièce 50, Rapport du ministère des colonies au Premier Consul en fructidor an IX [août-septembre 1799].

148. Mémoire pour le chef de brigade Magloire Pélage, et pour les habitans de la Guadeloupe, Desenne, thermidor an XI (août 1803), tome II, p. 6-7, Pièce $n^{\circ} 2$, procès-verbal de l'assemblée des citoyens du Port de la Liberté, convoquée par le citoyen Pélage, chef de brigade, commandant l'arrondissement de la Grande-Terre.

149. Ibid., p.65-66, Pièce 61, Extrait du registre de l'agence municipale de Port-de-la-Liberté (Pointe-à-Pitre), le 21 brumaire an X (12 novembre 1801).

150. Ibid., p. 64-84.

151. ADG, Notariat Serane, Minute du 23 brumaire an $X$ [14 novembre 1801], protestation des citoyens Labat, Toussaint Lorger, Michel Lacroix, Jean Baptiste Loisel, citoyens de Morne-à-l'Eau ; ADG, Notariat Serane, Minute du 23 brumaire an X [14 novembre 1801], protestation des citoyens Phamphile, greffier et Pierre Bourdon, citoyens de Morne-à-l'Eau.

152. Second mémoire des habitans de la Guadeloupe contre le général Lacrosse, Bordeaux, chez PellierLawalle, imprimeur libraire, rue du chapeau-rouge, an X, 44 p., Lettre du Conseil provisoire au Premier consul, le 24 brumaire an X (15 novembre 1801).

153. Mémoire pour le chef de brigade Magloire Pélage... op. cit., tome II, p. 92, Pièce 88, Arrêté du Conseil provisoire du 25 brumaire an X (16 novembre 1801).

154. Philippe GIRARD, Ces esclaves qui ont vaincu Napoléon, Bécherel, Les Perséides, 2013, p. 55-65.

155. Philippe GIRARD, « Napoléon voulait-il rétablir l'esclavage en Haïti?», Bulletin de la Société d'histoire de la Guadeloupe, 2011, n 159, p. 3-28

156. Frédéric RÉGENT, Esclavage, métissage, liberté, op. cit., p. 420-424.

157. Claude WANQUET, op. cit., tome III, p. 482. 
158. Jean-François NIORT, Jérémy RICHARD, «Bonaparte et le processus de rétablissement de l'esclavage à la Guadeloupe (1802-1803): essai de reconstitution à partir de découvertes archivistiques récentes ", Cahiers aixois des droits de l'outre-mer français, $\mathrm{n}^{\circ}$ 4, 2012.

159. ANOM, COL C14/88, $n^{\circ} 68$ n, Décret pris par les consuls sur le rapport du ministre de la Marine et des Colonies tendant à l'établissement d'un registre général des circonscriptions de quartiers (16 frimaire an XI [7 décembre 1802]). Mes remerciements à Yerri Urban qui m'a signalé ce document.

160. ANOM, COL C14/82, $\mathrm{F}^{\circ} 91$, Proclamation d'Hugues aux habitants concernant sa décision de modifier l'arrêté des Consuls du 16 frimaire an XI (7 décembre 1802), 9 prairial an XI (29 mai 1803). Mes remerciements à Yerri Urban qui m'a signalé ce document.

161. Frédéric RÉGENT, «Pourquoi faire l'histoire de la Révolution française par les colonies?", dans Jean-Luc Chappey, Bernard Gainot, Guillaume Mazeau, Frédéric Régent, Pierre Serna, Pour quoi faire la Révolution, Marseille, Agone, 2012, p. 80.

162. Jean-François N IORT, Jérémy RICHARD, «De la Constitution de l'an VIII [1799] au rétablissement de l'esclavage (1802) et à l'application du Code civil dans les colonies françaises (1805)... », art. cit., p. 174-175.

163. Josette FALLOPE, Esclaves et citoyens, les Noirs à la Guadeloupe au XIXe siècle, Basse-Terre, Société d'histoire de la Guadeloupe, 1992. p. 228-232 et 284-285.

164. Ibid., p. 286.

165. Yerri URBAN, « La citoyenneté dans l'empire colonial français est-elle spécifique ? », art. cit., 166. Charles Bisette est un métis libre de la Martinique qui s'est mobilisé de 1823 à 1833 pour l'obtention de la citoyenneté pour les libres de couleur, puis à partir de 1832, pour l'abolition de l'esclavage. Sa mère est une métisse dont le père naturel est également le père légitime de Joséphine de Beauharnais. Stella PAME, Cyrille Bissette. Un martyr de la liberté, Fort-de-France, Éditions Desormeaux, 1999.

\section{RÉSUMÉS}

L'un des enjeux de la Révolution française est la définition du périmètre de la citoyenneté dans le corps social. Les particularités des sociétés coloniales sont un défi aux différentes assemblées chargées de légiférer sur les droits du citoyen. L'objectif de cet article est de montrer de quelle manière les différents acteurs de la Révolution vont s'emparer et traiter la question de la citoyenneté dans les colonies de 1789 à 1848. L'obtention d'une députation par les représentants des riches planteurs à Paris, révèle la puissance de leur groupe de pression. Le contexte révolutionnaire mêlé à la concurrence sociale et l'idéologie raciste fixiste naissante expliquent la violence avec laquelle la citoyenneté des libres de couleur est combattue. L'obtention de la citoyenneté active par les gens de couleur libres s'explique par leur mobilisation armée à SaintDomingue, l'arrivée au pouvoir des philanthropes à Paris et la volonté de s'assurer un allié pour vaincre la révolte des esclaves d'août 1791. Le contexte de guerre civile et internationale transforme des esclaves, déjà massivement armés en citoyens. Il y a dans la législation du Directoire, volonté de permettre les mêmes modalités d'accès à la citoyenneté sur le territoire européen et dans l'outre-mer. A l'inverse, le Consulat place les colonies dans un régime de spécificité législative et remet en cause la citoyenneté des hommes de couleur en 1802. Cette 
citoyenneté n'est rétablit qu'en 1833 pour les hommes libres et est étendue aux esclaves en 1848, à la suite de deux nouvelles révolutions.

One of the challenges of the French Revolution is the definition of the scope of citizenship in the social body. The peculiarities of colonial societies are a challenge to the various assemblies loaded to legislate on the rights of the citizen. The objective of this article is to show how the different actors of the Revolution will capture and treat the question of citizenship in the colonies from 1789 to 1848 . Obtaining a deputation by the representatives of rich planters in Paris, reveals the power of their lobby. The revolutionary social context involved in competition and the inipient fixed racist ideology explain the violence with which the citizenship of color is fought free. Obtaining active citizenship by free people of color reflects their mobilization army in Santo Domingo, came to power in Paris and philanthropists will ensure an ally to defeat the slave revolt of August 1791 The context of civil and international war transforms slaves massivmeent armed in citizens. The legislation's Directory allow the same terms of access to citizenship in the European territory and in the overseas territories. Conversely, the Consulate instead settlements in a specific legislative regime and calls into question the citizenship of free coloured in 1802. This citizenship is not restored until 1833 for free men and slaves is extended to 1848 , following two new revolutions.

\section{INDEX}

Mots-clés : citoyenneté, libre de couleur, esclave, colonies, Révolution, Toussaint Louverture, Napoléon Bonaparte, Brissot

Keywords : citizenship, libre de couleur, slave, colonies, Revolution, Toussaint Louverture, Napoléon Bonaparte, Brissot

\section{AUTEUR \\ FRÉDÉRIC RÉGENT}

IHRF-IHMC 